\title{
Cold Rotary Forging of Inconel 718
}

\author{
Paranjayee Mandal ${ }^{1 a^{*}}$, Himanshu Lalvani $^{1 \mathrm{~b}}$, Martin Tuffs $^{2 \mathrm{c}}$ \\ paranjayee.mandal@strath.ac.uk ${ }^{\mathrm{a}}$; himanshu.lalvani@strath.ac.uk ${ }^{\mathrm{b}} ; \underline{\text { Martin.Tuffs@Rolls-Royce.com }}^{\mathrm{c}}$
}

\author{
${ }^{1}$ Advanced Forming Research Centre, University of Strathclyde, 85 Inchinnan Drive, \\ Inchinnan, Renfrewshire, PA4 9LJ, UK \\ ${ }^{2}$ Rolls-Royce, Derby, DE24 8BJ, UK \\ *Corresponding author
}

\begin{abstract}
The present work includes an in-depth study of microstructure and mechanical property development in a cold rotary forged component manufactured from Inconel 718 alloy. This work is pioneering in that there is no detailed study available in the literature focussing on cold rotary forging of Inconel 718. A tubular preform of $6 \mathrm{~mm}$ wall thickness was cold rotary forged into a 90 degree flange part followed by annealing with double aging. The present study provides a thorough analysis of microstructure, hardness and surface roughness evolution from as-received to final cold rotary forged and heat-treated condition including crystallographic texture changes occurring at different stages. The solution-annealed condition of the preform was found to be most suitable for cold rotary forging of Inconel 718. An annealing treatment followed by double-aging imparted desired properties such as homogeneous microstructure, uniform hardness distribution and improved surface roughness into the cold rotary forged Inconel 718 flange. The cold rotary forging can be a cost-effective route for manufacture of axisymmetric components with high material yield and low buy-to-fly ratio for expensive materials such as Inconel 718.
\end{abstract}

Keywords: Cold rotary forging; Inconel 718; Microstructure; Texture evolution; Hardness; Surface roughness. 


\section{Introduction}

Rotary forging is one of the incremental bulk forming processes where the material goes through localised deformation at cold or high temperature. Since the load requirements are lower due to the localised deformation, large components can be rotary forged on machines with relatively smaller load tonnage capacity. Semiatin [1] described that in rotary forging, the axis of the upper die was tilted at a slight angle with respect to the axis of the lower die. As a result, when one die was rotated relative to the other, the forging force was applied only to a small area of the work piece. The contact area between die and work piece was continually progressed through the work piece with rotation of the dies. The combination of the rotational movement and axial translation of the upper die gradually deformed the work piece until a final shape was formed. This method helps in achieving near net-shape geometries in one step leading to minimisation of both material and tooling costs. Both Semiatin [1] and Han and Hua [2] effectively summarised the advantages of rotary forging over conventional forging as high level of accuracy in single operation, precise geometrical tolerances, better surface finish, reduced friction between work piece and dies, reduced tool wear, faster production rate and reduced energy consumption. Now-a-days rotary forging has become a substitute for conventional forging especially in case of producing thin discs and large flanges having high diameter-to-thickness ratio. Reports by Semiatin [1] and Aksenov and Kunkin [3] indicate that approximately one-quarter to one-third of all parts that are either hammer or press forged could be formed on a rotary forge, however the rotary forge applications are limited to the production of only axisymmetric parts at present.

Alloy steels are observed as most common choice for rotary forging, particularly cold rotary forging, due to their adequate ductility. Several researchers had studied the cold rotary forging of steels and the focus was mainly on the process modelling as well as understanding the microstructural evolution. For example, Han and Hua [2] developed a 3D elastic-plastic dynamic explicit FE model for cold rotary forging of a cylindrical work piece and validated the model using experimental results, Han et al. [4] studied the microstructural evolution including texture of a cold rotary forged spur bevel gear made of a ferritic - pearlitic steel and Pérez [5] studied the same for cold rotary forging of a martensitic stainless steel, Jethete M152, with different flange thicknesses. These examples indicate the wide range of research already conducted on cold rotary forging of steels. Beside steels, Inconel 718 (IN718) has attracted specific attention of researchers for rotary forging due to its wide-spread application in 
manufacture of turbine disks for aerospace engines and gas turbines. Slama and Abdellaoui [6] and Akca and Gursel [7] mentioned that high yield strength, impact strength and fracture toughness, good corrosion resistance and weldability and a service temperature up to $650^{\circ} \mathrm{C}$ made IN718 suitable for such applications. Till date, the rotary forging of IN718 has been attempted in the temperature range of $950^{\circ} \mathrm{C}-1100^{\circ} \mathrm{C}$ as reported by several authors [8-11] as elaborated here. Domblesky and Shivpuri [8] used a Gleeble 1500 thermo-mechanical testing system to simulate the rotary forging process of a $28 \mathrm{~mm}$ thick IN718 disk and estimated the grain size in the temperature range of $954^{\circ} \mathrm{C}-1066^{\circ} \mathrm{C}$. They observed that the applied strain per pass and the forging temperature were two primary factors controlling recrystallized grain size, which was in the range of ASTM 4 -9. Zhong-Qi et al. [9] mentioned that the grain size evolution during rotary forging process was controlled by several rotary forging parameters, such as, the ratio of initial height to diameter, the angle of the upper die and the relative feed per revolution etc. The flow behaviour of IN718 was particularly dependant on the grain size showing a strong influence on the deformation mechanisms, such as, dynamic recrystallization, recovery and grain growth. They proposed a constitutive equation and a microstructural model considering the effects of strain hardening, dynamic recovery and recrystallization to describe the flow behaviour of an IN718 disk in the temperature range of $975^{\circ} \mathrm{C}-1050^{\circ} \mathrm{C}$. They observed a strong effect of ratio of initial height to diameter in controlling grain size especially at the central region as compared to other parameters and grain size at any other section. Mangas et al. [10] focussed on developing a similar microstructural model to predict the grain size of IN718 cylindrical billets during rotary forging at $\sim 1100^{\circ} \mathrm{C}$. Based on the prediction of the FEM simulation model developed by Tecnalia, they modified the process parameters to obtain a uniform grain size distribution within the part. They observed presence of DRX during deformation of material by the upper die whereas MDRX appeared after recrystallization process when DRX stopped due to lack of deformation. They found no significant effect of initial grain size (ASTM $2-4$ ) when the recrystallization was guaranteed (i.e. final grain size was observed in the range of ASTM 1 - 10). Recently, Loyda et al. [11] modelled the characteristic changes in grain size of IN718 disks during rotary forging in the temperature range of $980^{\circ} \mathrm{C}-1050^{\circ} \mathrm{C}$ using Johnson-Mehl-Avrami-Kolmogorov (JMAK) model or typically known as Avrami model in DEFORM 3D. They observed a significant dependency of grain size on the initial temperature, strain rate, effective strain, and recrystallized fraction of grains. This JMAK-type models could successfully address possible microstructural changes during relatively slow forging of objects having simple geometry, however they were not effective in simulating industrial forging process, such as rotary forging, which involved 
complex strain paths and thermo-mechanical histories. It should be noted that in each of the above-mentioned literature, either a disk or a cylindrical billet was rotary forged in the temperature range of $950^{\circ} \mathrm{C}-1100^{\circ} \mathrm{C}$ and attention was given mostly on the microstructural modelling in order to predict and optimise the grain size. There is a lack of available information in the literature on microstructural evolution of IN718 during rotary forging process and unlike alloy steels, no studies have been reported yet particularly on cold rotary forging of IN718.

The use of rotary forging is commonplace in many industrial sectors for components such as hubs, pistons and bearings. These applications benefit from the ability of rotary forging to produce large diameter features, such as flanges, from standard smaller diameter bar. The same benefits are applicable to engine applications and with high value materials, such as IN718, the efficiencies can be maximised. This work is the first study of its kind, which demonstrates the cold rotary forging of Inconel 718 flange and describes the associated microstructural evolution, hardness distribution and surface roughness properties. Until now the hot forging and hot rotary forging of IN718 have been extensively studied on different disk and cylindrical billets, however no work has been reported yet on cold rotary forging of IN718 axisymmetric flange. The novelty of this work lies in the selection of (i) a unique and cost-efficient manufacturing process (i.e. cold rotary forging), (ii) an expensive work piece material (i.e. IN718), (iii) a new work piece geometry (i.e. $6 \mathrm{~mm}$ thick hollow cylinder, where $6 \mathrm{~mm}$ is the required thickness of a 90 degree bend flange for its final application) and (iv) an efficient heattreatment process (i.e. annealing followed by double-aging) to improve properties of the cold rotary forged flange. Combining all of the above key factors in order to manufacture an IN718 flange with 90 degree bend at cold condition (temperature range $\sim 20^{\circ} \mathrm{C}-120^{\circ} \mathrm{C}$ ) ensures no material waste, no post-processing operation and reduces the degradation of forming dies due to less thermal fatigue and wear, leading to a reduction in overall manufacturing time and cost.

\section{Cold rotary forging of IN718}

In this work, a solution-treated IN718 cylindrical bar having a diameter of 4 inches and a length of 4.1 inches was supplied by Rolls Royce Plc. and was considered as as-received material. The solution annealing was done in the range of $950^{\circ} \mathrm{C}-980^{\circ} \mathrm{C}$ (according to $\mathrm{RR}$ specification MSRR7115) in order to take the advantage of precipitation hardening. The core of the asreceived IN718 bar was cut through by wire EDM in such a way that a $6 \mathrm{~mm}$ thick hollow 
cylinder can be obtained from that, where $6 \mathrm{~mm}$ was the required thickness of the flange for final application. This hollow cylinder was then used as the preform for cold rotary forging.

The cold rotary forging of $6 \mathrm{~mm}$ thick hollow IN718 cylinder was performed on an MJC Rotary Forge RFN 200T-4 press in Advanced Forming Research Centre in Scotland, UK. This press is able to rotary forge axisymmetric parts with minimum and maximum diameters of $50 \mathrm{~mm}$ and $400 \mathrm{~mm}$ respectively. Figure 1 shows a schematic of the start and end points of the cold rotary forging process for the manufacture of a 90 degree bend IN718 flange. Initially, the 6 $\mathrm{mm}$ thick hollow cylinder was placed into the bottom tool and the top conical forging tool was moved downwards to approach the hollow cylinder at a shallow angle (typically between $0^{\circ}-$ $10^{\circ}$ ). Then the conical forging tool made contact with the inner face of the hollow cylinder and incrementally deformed (i.e. flaring) the cylinder to a certain depth. At the end of the cold rotary forging process, the conical forging tool was nutated fully to the required angle such that the forging face of the conical tool was parallel to the top of the bottom tool to get a 90 degree bend flange. The process variables that influenced the flange manufacturing were forging tool cone angle, flaring angle, forging feed rate, nutation method, nutation angle, nutation feed rate and spindle velocity. In this work, the cold rotary forging of IN718 flange was started at the room temperature $\left(\sim 20^{\circ} \mathrm{C}\right)$ and then the maximum temperature was observed as $\sim 120^{\circ} \mathrm{C}$ at the end of the process. A LAND-ARC thermal imaging camera with a temperature tolerance of $\pm 5^{\circ} \mathrm{C}-10^{\circ} \mathrm{C}$ was used to measure the temperature throughout the cold rotary forging process. Figure 2 shows the thermal image of IN718 cold rotary forged flange indicating the temperature distribution along the flange section. The temperature profile in the inset shows that the minimum and maximum temperatures of the flange are observed as $\sim 33^{\circ} \mathrm{C}$ and $\sim 117^{\circ} \mathrm{C}$ respectively after cold rotary forging (note that the image has been captured when the flange is still in between top and bottom tools of the forging press exactly after cold rotary forging). Figure 3 shows the top and side view of the cold rotary forged flange part once the part is cooled and taken out of the MJC Rotary Forge press. 


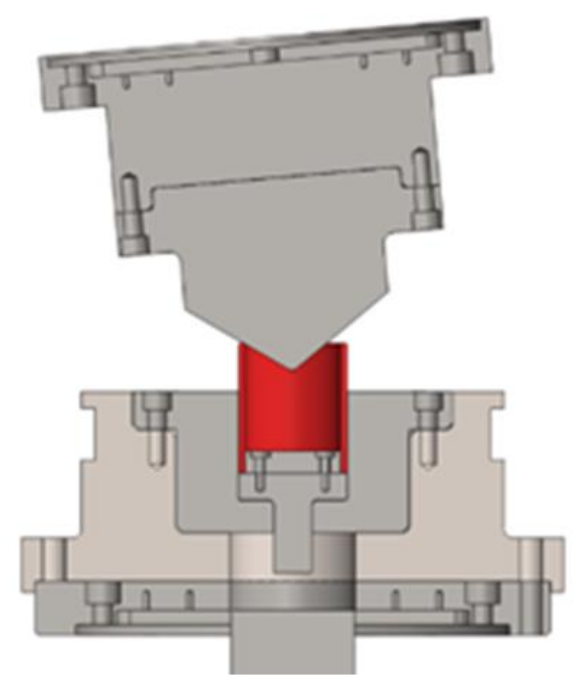

(a)

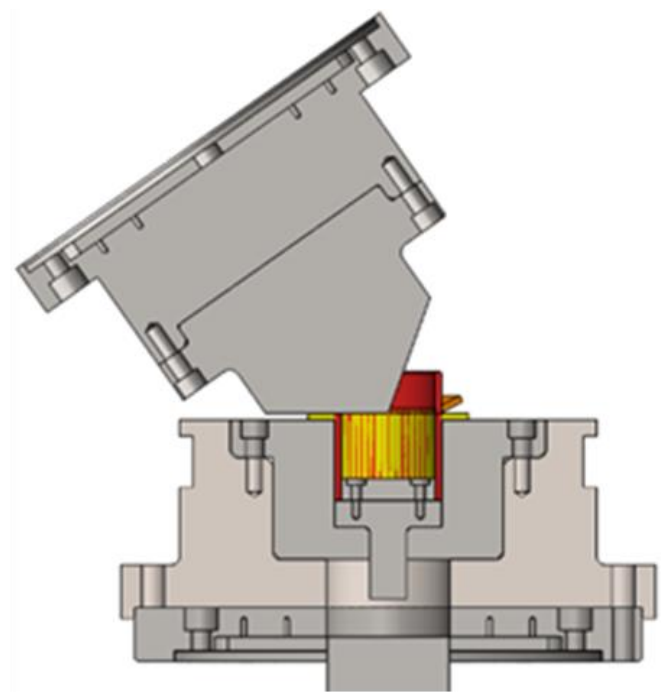

(b)

Figure 1: Schematic indicating the (a) start point and (b) end point of AFRC's cold rotary forging process during manufacture of a 90 degree bend IN718 flange

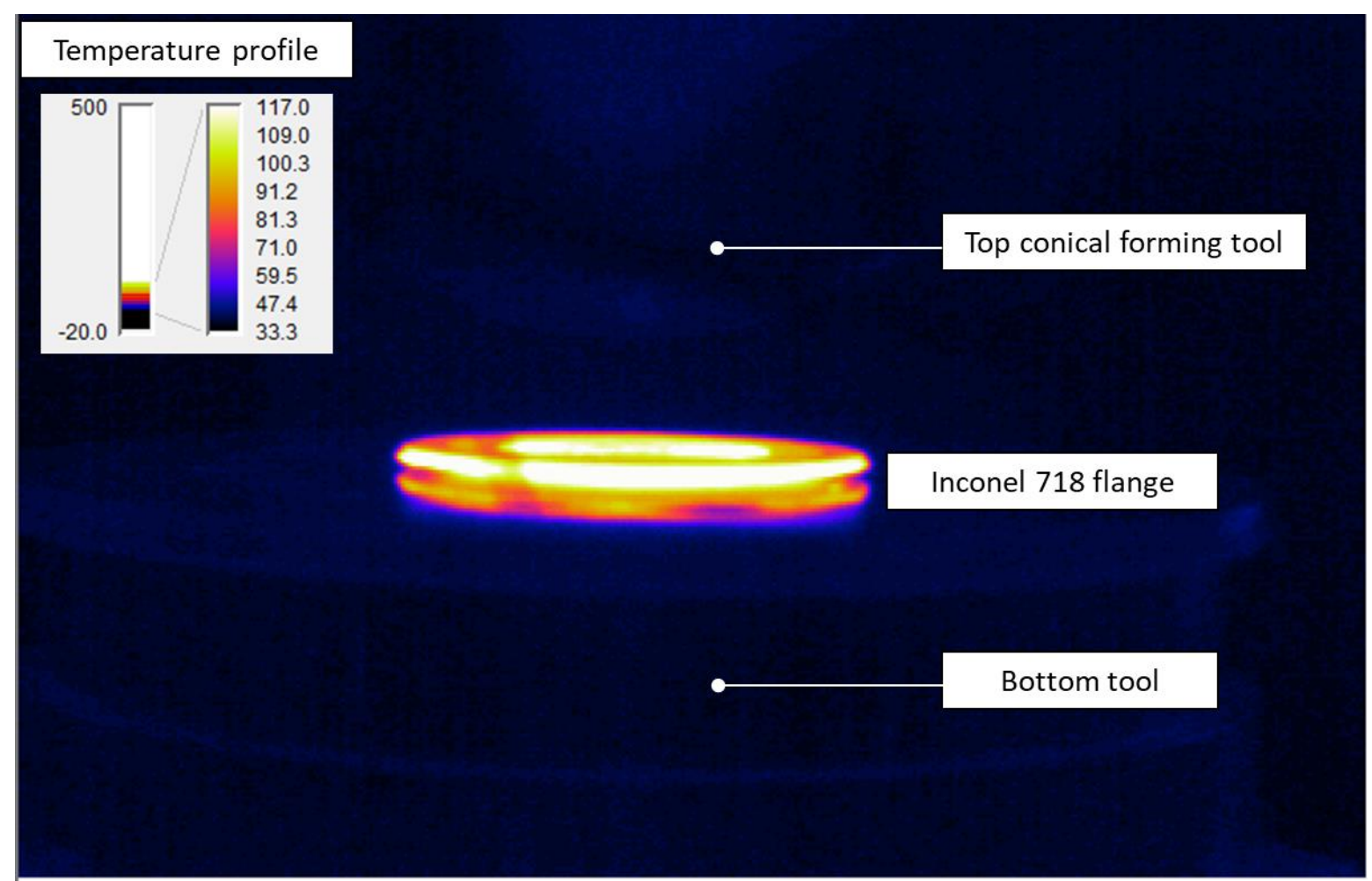

Figure 2: Thermal image of IN718 cold rotary forged flange showing the temperature distribution along the flange section 

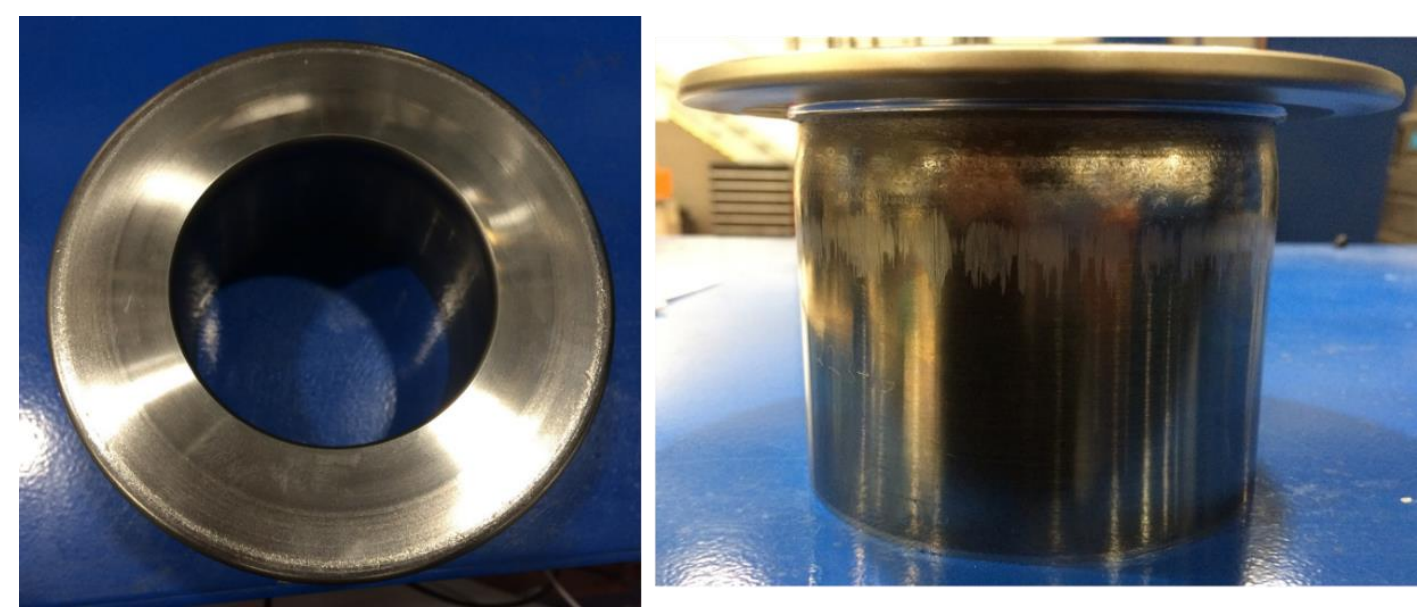

Figure 3: The top (on left) and side (on right) view of the cold rotary forged flange (images are not to scale because of IP restriction)

\section{Experimental details}

The chemical composition of the as-received solution annealed IN718 bar is provided in Table 1. As already mentioned, the core of the cylindrical IN718 bar was cut by the wire EDM and two cross-sections were then extracted from the centre and periphery of the core cylinder. Both cross-sections represented the as-received material properties (hereafter termed as asR), however the sample extracted from the periphery was closer to the final flange part in terms of microstructure rather than the sample extracted from the centre of the core cylinder. The reason behind selecting these two cross-sections was to understand the presence of any inhomogeneity in microstructure (mainly in terms of grain size) from the centre to the periphery, as it was normally expected due to the difference in cooling rate, following billet forging and after solution annealing, from the centre to the periphery of any bulk cylinder.

Table 1: Chemical composition of IN718 as-received bar

\begin{tabular}{|c|c|c|c|c|c|c|c|c|}
\hline Elements & $\mathrm{C}$ & $\mathrm{Si}$ & $\mathrm{Mn}$ & $\mathrm{P}$ & $\mathrm{S}$ & $\mathrm{Al}$ & $\mathrm{Cr}$ & $\mathrm{Cu}$ \\
\hline Wt\% & $0.02-$ & $<0.35$ & $<0.35$ & $<0.015$ & $<0.015$ & $\begin{array}{c}0.3- \\
0.7\end{array}$ & $17-21$ & $<0.2$ \\
& 0.08 & & & & & \multicolumn{4}{|c|}{ Re } \\
\hline Elements & $\mathrm{Mo}$ & $\mathrm{Ti}$ & $\mathrm{Ni}+\mathrm{Co}$ & $\mathrm{Nb}+\mathrm{Ta}$ & \multicolumn{4}{|c|}{} \\
\hline Wt\% & $2.8-3.3$ & $\begin{array}{c}0.7- \\
1.15\end{array}$ & $50-55$ & $4.75-5.5$ & \multicolumn{4}{|c|}{} \\
\hline
\end{tabular}




\subsection{Heat-treatment of the cold rotary forged part}

After the EDM cut, the IN718 tube with $6 \mathrm{~mm}$ wall thickness was used for cold rotary forging as already described in Section 2. The heat-treatment is typically applied either in between the cold rotary forging passes or at the end of the cold rotary forging process in order to restore ductility. In this work, the heat-treatment was applied on the cold rotary forged part (i.e. after the cold rotary forging process) to achieve a uniform hardness distribution throughout the flange meeting the hardness requirement (>361 HV) as per the material specification. A certain number of flanges were formed in each batch and one flange from the same manufacturing batch was heat-treated, in an in-house Carbolite furnace, to the Rolls-Royce specification that involved - (i) annealing at $980^{\circ} \mathrm{C}$ for 30 minutes, (ii) followed by aging at $720^{\circ} \mathrm{C}$ for 8 hours with a cooling to $620^{\circ} \mathrm{C}$ at $50^{\circ} \mathrm{C} /$ hour rate, (iii) followed by 8 hours air cooling from $620^{\circ} \mathrm{C}$ (according to RR specification MSRR7115). Candioto et al. [12] summarised that the purpose of annealing treatment was to recrystallize and homogenise the microstructure, to dissolve the carbides in the grain boundaries and to accelerate the grain growth for increasing creep-rupture resistance. The aging treatment was used to increase the material strength by precipitation of additional quantities of the second phases as developed by solution annealing. For IN718, more than one phase could precipitate at a time, thus double aging was preferred in order to enhance the formation of both $\gamma^{\prime}\left(\mathrm{Ni}_{3} \mathrm{Ti}, \mathrm{Al}\right)$ and $\gamma^{\prime \prime}\left(\mathrm{Ni}_{3} \mathrm{Nb}\right)$ phases. Wang and $\mathrm{Li}$ [13] observed the structural dependence of IN718 on different types of double aging techniques and reported that the $720^{\circ} \mathrm{C} / 8$ hours $+620^{\circ} \mathrm{C} / 8$ hours was the best aging treatment as it formed higher amount of $\gamma^{\prime}$ and $\gamma^{\prime \prime}$ phase precipitates along with lowest amount of $\delta$ phase ( $\mathrm{Ni}_{3} \mathrm{Nb}$ orthorhombic). Kishan and Nagarajan [14] reported that the $\gamma^{\prime \prime}$ was precipitated during the first aging at $720^{\circ} \mathrm{C}$, whereas formation of $\gamma^{\prime}$ was observed in the areas between $\gamma^{\prime \prime}$ phases during second aging at $620^{\circ} \mathrm{C}$. Slama and Abdellaoui [6] observed that the FCC $\gamma^{\prime}$ phase was appeared as a fine dispersion into the $\gamma$ matrix and was termed as auxiliary strengthening phase, whereas the long disc-shaped BCT $\gamma^{\prime \prime}$ phase was lied parallel to the $\{100\}$ slip plane of the $\gamma$ matrix and was known as the main strengthening phase. The formation of both $\gamma^{\prime}$ and $\gamma^{\prime \prime}$ phase precipitates was dependant on a number of factors including stacking faults of the crystalline lattice and chemical composition. Maj et al. [15] observed that a minor decrease in Nb content and a slight increase in $\mathrm{Al}$ and $\mathrm{Ti}$ contents led to direct nucleation of $\gamma^{\prime}$ instead of $\gamma^{\prime \prime}$, resulting in a significant reduction in strength at elevated temperature. Apart from the $\gamma^{\prime}$ and $\gamma^{\prime \prime}$ phase precipitates, Kishan and Nagarajan [14] observed formation of a stable $\delta$ phase when exposed to temperatures above $650^{\circ} \mathrm{C}$ and Maj et al. [15] reported direct formation of $\delta$ phase from the 
$\gamma$ matrix in the temperature range of $900^{\circ} \mathrm{C}-950^{\circ} \mathrm{C}$. In addition to this, Candioto et al. [12], Kishan and Nagarajan [14] and Maj et al. [15] pointed out that the nucleation of $\delta$ phase was mainly occurred at the grain boundaries leading to heterogeneous weakening of the material, low ductility, reduction in the maximum elongation during tensile test, an increase in brittleness and hindrance in the grain growth. Thus $\delta$ phase formation was considered detrimental for cold rotary forging operation. In this study, the as-received material was solution-treated in the range of $950^{\circ} \mathrm{C}-980^{\circ} \mathrm{C}$ and after cold rotary forging, it was further annealed at $980^{\circ} \mathrm{C}$ for 30 minutes, thus there was always a fair chance for $\delta$ phase formation. However, the double aging treatment helps in limiting the proportion of $\delta$ phase and promotes formation of more amount of $\gamma^{\prime \prime}$ phase precipitates leading to higher strength of the part.

\subsection{Sample preparation}

Both the cold rotary forged flange and the cold rotary forged and heat-treated flange were sectioned by wire EDM into four longitudinal slices of $1 \mathrm{~cm}$ width as shown in Figure 4. One of these four slices from each flange part was further cut into four sections (sections $1-4$ as shown in Figure 4) of slightly different length by a Buehler Abrasimatic 300 abrasive cutter. The four sections were selected in such a way that they together provided a complete picture of microstructural evolution of IN718 flange parts during cold rotary forging operation and related heat-treatment. In total, there were ten sections for metallurgical preparation - two asR cross-sections extracted from the centre and the periphery of the core cylinder respectively, sections $1-4$ from the cold rotary forged part (hereafter termed as $\mathrm{CF}$ ) and sections $1-4$ from the cold rotary forged and heat-treated part (hereafter termed as $\mathrm{CF}+\mathrm{HT}$ ). It should be noted here that the section 2 of both the $\mathrm{CF}$ and $\mathrm{CF}+\mathrm{HT}$ parts were of most interest here as they contained a sharp 90 degree bend in order to form the flange. All the above-mentioned asR, $\mathrm{CF}$ and $\mathrm{CF}+\mathrm{HT}$ sections were then mounted in separate conductive moulds followed by grinding and polishing using a Buehler IsoMet 5000 machine. Different SiC abrasive grit papers (P240, P400, P800, P1200) were used for grinding whereas polishing was done using a UltraPol 9 $\mu \mathrm{m}$, Trident $3 \mu \mathrm{m}$, MasterTex $1 \mu \mathrm{m}$ and Microcloth with $0.02 \mu \mathrm{m}$ colloidal silica suspension. The polished asR and CF sections were then electro-etched using 10\% oxalic acid (in dilution with water) at $4 \mathrm{~V}$ and 0.6 amps (using DC power supply) in order to reveal the grain structure using optical microscope. Full surface area of all sections were electro-etched for 1-2 seconds and then repeated until successful result was achieved, i.e. about 15 seconds for one section. For etching of $\mathrm{CF}+\mathrm{HT}$ sections, a number of etchants were tried to reveal the grain boundary as 
listed in Table 2, however only 'micro etch' was proved most successful in revealing the grain boundary properly.

Top view of the flange part

Side view of the cut pieces

Four slices of $1 \mathrm{~cm}$ width is cut for metallurgical analysis
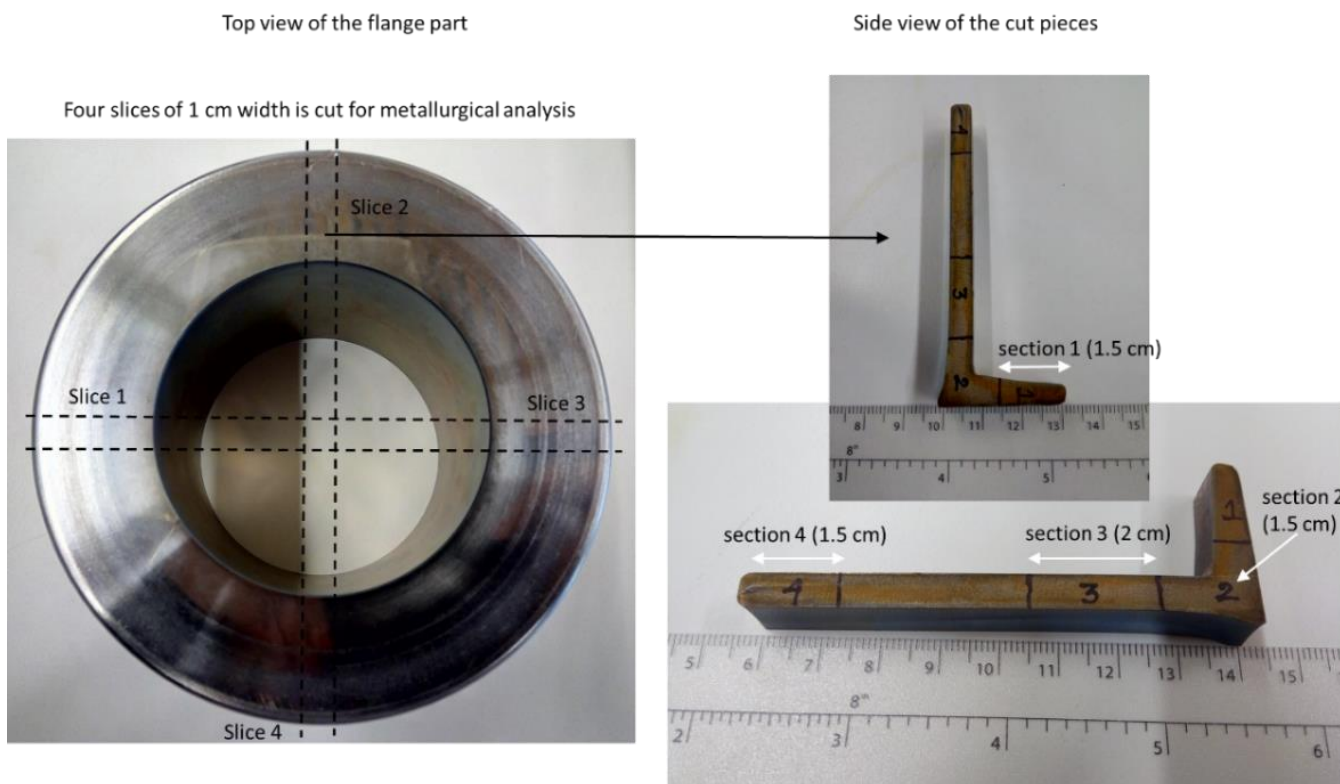

Figure 4: Sample cutting scheme of the cold rotary forged flange before and after heattreatment for metallurgical analysis

Table 2: List of etchants used to reveal the grain boundary of $C F+H T$ IN718 sections

\begin{tabular}{|c|c|c|}
\hline Etchant name & Composition & $\begin{array}{l}\text { Ability to reveal } \\
\text { grain boundary }\end{array}$ \\
\hline $\begin{array}{l}\text { Aqua regia (ASTM } \\
\text { standard no. 12) }\end{array}$ & $20 \mathrm{ml} \mathrm{HNO}_{3}$ with $60 \mathrm{ml} \mathrm{HCl}$ & No \\
\hline $\begin{array}{l}\text { Ralphs reagent (ASTM } \\
\text { standard no. 221) }\end{array}$ & $\begin{array}{c}50 \mathrm{ml} \mathrm{H}{ }_{2} \mathrm{O}, 50 \mathrm{ml} \text { ethanol, } 50 \mathrm{ml} \\
\text { methanol, } 50 \mathrm{ml} \mathrm{HCl}, 1 \mathrm{~g} \mathrm{CuCl}_{2}, 2.5 \mathrm{~g} \\
\mathrm{FeCl}_{3}, 2.5 \mathrm{ml} \mathrm{HNO}_{3}\end{array}$ & No \\
\hline $\begin{array}{l}\text { Acetic glyceregia (ASTM } \\
\text { standard no. 89) }\end{array}$ & 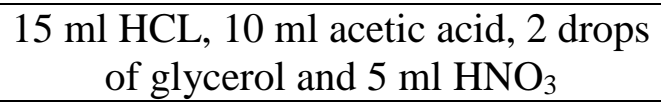 & No \\
\hline $\begin{array}{c}\text { Glyceregia (ASTM standard } \\
\text { no. 87) }\end{array}$ & $\begin{array}{c}50 \mathrm{ml} \mathrm{HCl}, 30 \mathrm{ml} \text { glycerol, } 10 \\
\mathrm{ml} \mathrm{HNO}_{3}\end{array}$ & No \\
\hline- & $2 \mathrm{ml} \mathrm{HCl}$ and $2 \mathrm{ml} \mathrm{C}_{2} \mathrm{H}_{2} \mathrm{O}_{4}$ & No \\
\hline 3 acid reagent & $\begin{array}{c}15 \mathrm{ml} \mathrm{HCl}, 10 \mathrm{ml} \text { acetic acid and } 10 \\
\mathrm{ml} \mathrm{HNO}_{3}\end{array}$ & No \\
\hline Micro etch (by immersion) & $\begin{array}{c}8 \mathrm{ml} \mathrm{HCl}, 0.4 \mathrm{ml} \mathrm{HF}, 1.6 \mathrm{ml} \mathrm{H}_{2} \mathrm{O}_{2} \text { and } \\
10 \mathrm{ml} \mathrm{H}_{2} \mathrm{O}\end{array}$ & Yes \\
\hline
\end{tabular}




\subsection{Microstructural characterisation - optical microscopy and EBSD}

The microstructural characterisation of each of these sections as extracted from asR, CF and $\mathrm{CF}+\mathrm{HT}$ parts was carried out using both optical and scanning electron microscopy. A number of optical images were collected using Leica DM1200M and the measurement was done according to ASTM standard E112 [16]. Figure 5 shows the schematic of locations for optical image collection in all sections of asR, $\mathrm{CF}$ and $\mathrm{CF}+\mathrm{HT}$ samples as indicated by the black dots. A number of images were captured from three different zones, i.e. inside, middle and outside, of each section to identify any variation in grain size and shape as a result of deformation during cold rotary forging process. Leica has an automatic software for detecting grain boundaries, however it failed to detect the grain boundaries properly due to presence of a lot of twin grain boundaries and presence of very fine surface waviness in the polished samples. In order to eliminate these problems, the grains were hand-traced to identify grain boundaries and then were scanned to generate a binary image showing outlines of the grain boundaries only. A set of Matlab codes were then used for best elliptical fitting of the grains and the generated output was the average grain size in terms of equivalent circle diameter. This method is known as tracing method. For average grain size calculation of each section, averaging is done based on a large number of grains $(\sim 1100$ for asR and $\sim 2400$ and $\sim 4600$ for all four CF and CF+HT sections respectively).

The asR cross-section extracted from the periphery of the core cylinder and section 2 of both $\mathrm{CF}$ and $\mathrm{CF}+\mathrm{HT}$ flange parts were then vibro-polished for 3 hours using a Buehler Vibromet vibratory polisher for EBSD analysis. The section2 was chosen for EBSD analysis as it represented the most deformed 90 degree bend section of the flange and the scanning was done exactly at the middle of that bend section. The EBSD data was collected using an FEI Quanta FEG 650 - SEM fitted with an Oxford instruments camera system and Aztec software operating with an accelerating voltage and working distance of $20 \mathrm{kV}$ and $20 \mathrm{~mm}$ respectively. Orientation mapping was performed on a rectangular grid with a step size of $1 \mu \mathrm{m}$ and the indexing rate was achieved mostly $\sim 99 \%$ for all three samples. The corresponding data processing, including grain size, area fraction of grains, average misorientation and texture analysis, was then carried out using HKL Channel5 post processing software. Only high angle grain boundaries (HAGB) with a misorientation angle of $\theta>15^{\circ}$ were detected in order to determine the average size of the most deformed grains as observed exactly at the middle of the 90 degree bend in section2. Humphreys [17] mentioned that the accepted grains in EBSD should contain at least 5 pixels and the same identification of minimum grain size was adopted 
in this current study. This indicates that a grain should have minimum $5 \mu \mathrm{m}^{2}$ area as the step size in this case was $1 \mu \mathrm{m}$. Anything less than that area was considered as noise and therefore was not included in the calculation of average grain size to avoid underestimation. The total number of grains covered during EBSD analysis were $\sim 1000, \sim 2500$ and $\sim 15000$ for asR, CF section 2 and $\mathrm{CF}+\mathrm{HT}$ section 2 samples respectively. The average misorientation between each individual point and its $4^{\text {th }}$ nearest neighbour kernels was calculated within a rectangular grid $(9 \times 9)$ and the threshold angle for sub-grains was considered as $2^{\circ}$. The processed data was used to plot the Kernel Average Misorientation (KAM) map. The KAM maps are often used to gain insight into the local lattice distortions, change in dislocation density and hence stored energy (or plastic strain) in the grain [18]. Since the process simulation is not within scope of the current work, therefore the KAM maps are used to understand the strain distribution within the most deformed section of the cold rotary forged part and the post-forging heat-treated part.

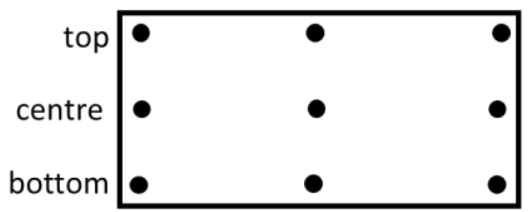

as $\mathrm{R}$ cross-sections extracted from the centre and periphery

(a)
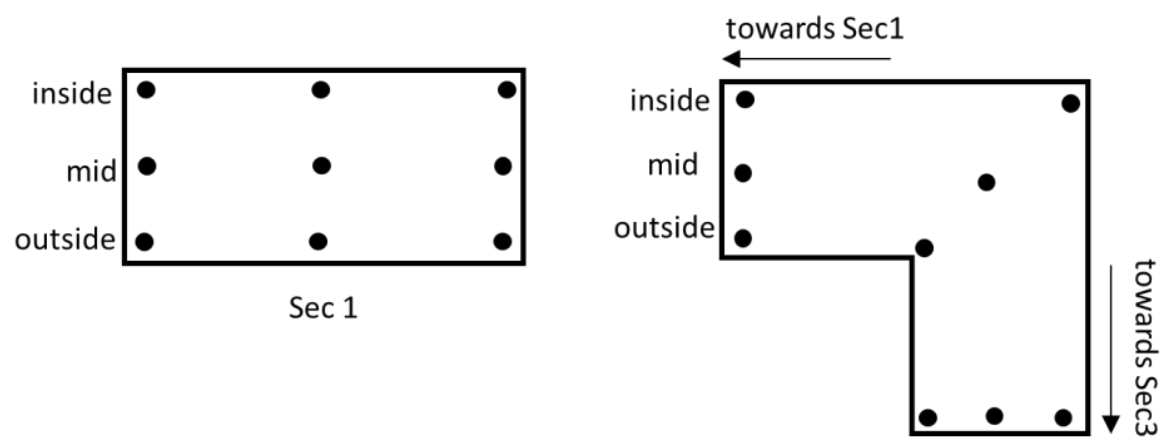

$\operatorname{Sec} 2$

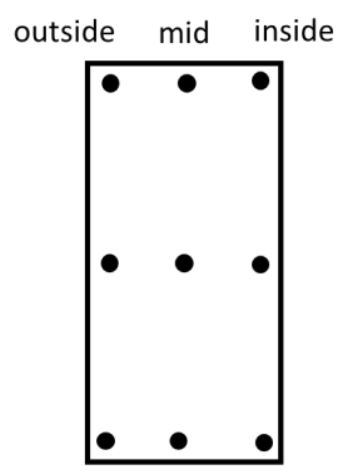

$\operatorname{Sec} 3$ and Sec 4 
Figure 5: Schematic of locations (black dots) for optical image collection- (a) both asR crosssections, (b) all four sections of both $C F$ and $C F+H T$ parts.

\subsection{Hardness measurement}

Hardness is a measure of material's resistance to permanent deformation, thus it characterises the strength of a material. In case of cold rotary forging process, the hardness of the preform (i.e. the material hardness prior to rotary forging) is a key indicator of suitability of the material for the process. Normally, lower hardness (better ductility) in the preforms is preferred for ease of rotary forging. Figure 6 shows the schematic of hardness maps of both asR cross-sections extracted from the centre and periphery (Figure 6a) and all four sections of both $\mathrm{CF}$ and $\mathrm{CF}+\mathrm{HT}$ samples (Figure 6b). The samples were mechanically polished before the hardness test. A Struers hardness tester was used to measure the hardness of all samples. In order to understand any existing variation in hardness through the cross section of the part before and after heat treatment, a rectangular matrix of 30 indents, i.e. 10 indents at inner diameter side (ID), at centre (C) and at outer diameter side (OD) of the flange respectively, was created on each section (except section2). Only section2 contains 12 indents at inner diameter side (ID), 10 indents at centre (C) and 8 indents at outer diameter side (OD) of the flange so that the indents are appropriately placed to capture the hardness of the $90^{\circ}$ bend section of the flange. The black dots show the indent positions on each of the sections. The indents were made using a Vickers indenter with a fixed load of $1 \mathrm{kgf}$. The distance between any two indents along both $\mathrm{X}$ and $\mathrm{Y}$ directions was kept as $0.5 \mathrm{~mm}$ for asR sections and $1 \mathrm{~mm}$ for both $\mathrm{CF}$ and $\mathrm{CF}+\mathrm{HT}$ sections. This ensured more than 3 diagonal widths spacing between any two indents as recommended for steel samples [19]. The average microhardness and standard deviation of all samples was calculated according to ASTM standard E384 - 11 [20]. 


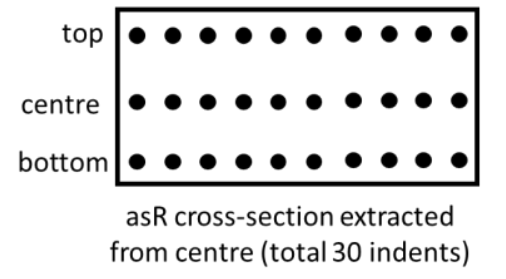

*for both CF and CF+HT parts

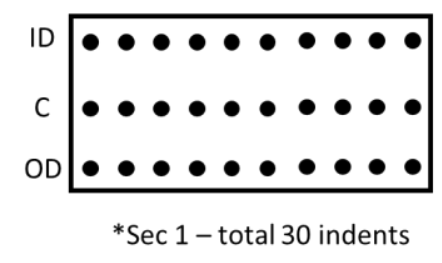

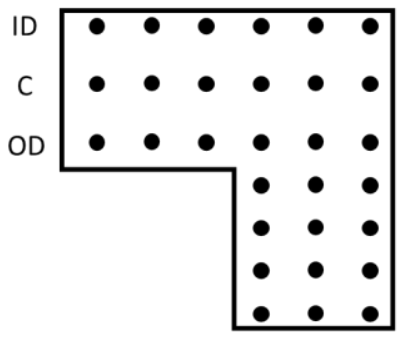

*Sec 2 - total 30 indents

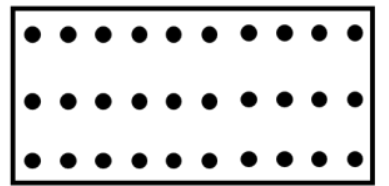

asR cross-section extracted from periphery (total 30 indents) (a)

*Sec 3 and $\sec 4-$ total 30 indents for each section

Figure 6: Schematic of hardness maps for (a) asR cross-sections extracted from the centre and periphery, (b) sections $1-4$ for both CF and CF+HT parts. The black dots show the indent positions.

\subsection{Surface roughness measurement}

Figure 7 shows the surface roughness measurement scheme of asR, CF and CF+HT parts. Alicona Infinite Focus IFM G4 surface profilometer was used to measure the surface roughness. The intention was to cover the entire length of the upper and lower flange surfaces as well as inner and outer wall surfaces. The measuring scheme includes three $5.6 \mathrm{~mm}$ long line scans on each of the surfaces in order to capture any variation of the surface roughness from asR (note that the roughness measurement is taken on the preform prior to rotary forging which is regarded as the as-received condition) to $\mathrm{CF}$ condition and after heat-treatment, i.e. $\mathrm{CF}+\mathrm{HT}$ condition. Each line scan provides $\mathrm{R}_{\mathrm{a}}$ (arithmetic mean deviation of the assessed profile), $R_{q}$ (root mean square value) and $R_{z}$ (average distance between the highest peak and lowest valley in each sampling length) values. The average of all three values were calculated for each surfaces and plotted accordingly. Table 3 summarises all the microstructural analysis performed on different IN718 sections for reader's convenience. 


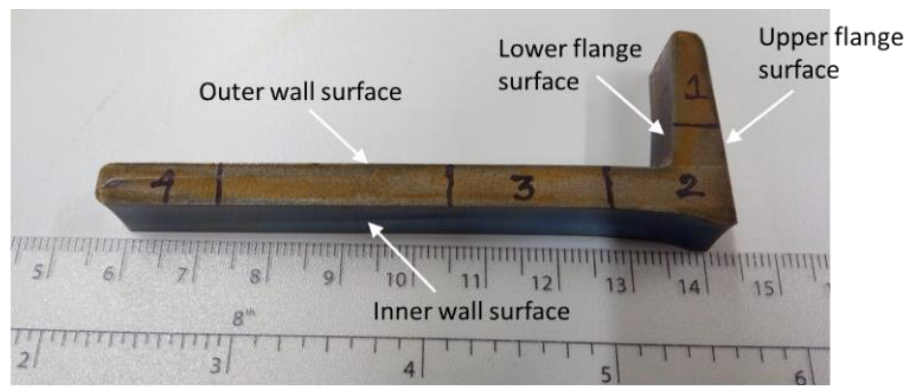

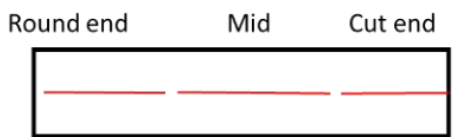

Upper flange surface (3 line scans)

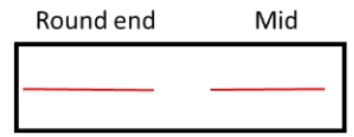

Lower flange surface (3 line scans)

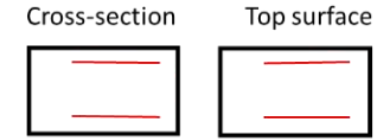

asR material ( 2 line scans on each section)

*Each line scan is $5.6 \mathrm{~mm}$ long and the red lines indicate the position of the line scans

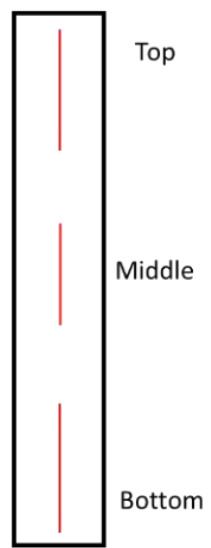

Inner wall surface (3 line scans)

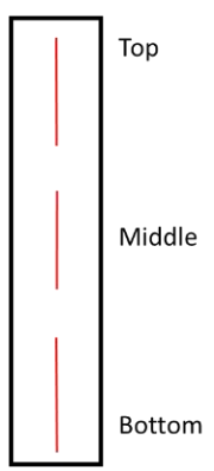

Outer wall surface (3 line scans)

Figure 7: Schematic of surface roughness measurement on as $R, C F$ and $C F+H T$ parts

Table 3: Summary of microstructural analysis performed on IN718 sections

\begin{tabular}{|c|c|c|c|}
\hline \multirow{2}{*}{$\begin{array}{c}\text { Microstructural } \\
\text { analysis }\end{array}$} & \multicolumn{2}{|c|}{ Samples and sections } \\
\cline { 2 - 4 } & as-received (asR) & $\begin{array}{c}\text { cold rotary } \\
\text { forged }(\mathbf{C F})\end{array}$ & $\begin{array}{c}\text { cold rotary forged } \\
\text { and heat-treated } \\
\text { (CF + HT) }\end{array}$ \\
\hline $\begin{array}{c}\text { Grain size analysis } \\
\text { from optical } \\
\text { microscopy }\end{array}$ & $\begin{array}{c}\text { Cross-sections } \\
\text { extracted from the } \\
\text { centre and periphery }\end{array}$ & Sections $1-4$ \\
\hline EBSD analysis & $\begin{array}{c}\text { Cross-section extracted } \\
\text { from the periphery }\end{array}$ & $\begin{array}{c}\text { Middle of section2 containing } 90 \\
\text { degree bend }\end{array}$ \\
\hline Texture analysis & $\begin{array}{c}\text { Cross-sections } \\
\text { extracted from the } \\
\text { centre and periphery }\end{array}$ & Sections $1-4$ \\
\hline $\begin{array}{c}\text { Hardness analysis } \\
\text { Turface roughness } \\
\text { analysis }\end{array}$ & $\begin{array}{c}\text { Top surface and cross- } \\
\text { section }\end{array}$ & $\begin{array}{c}\text { Upper and lower flange surfaces, outer } \\
\text { and inner wall surfaces }\end{array}$ \\
\hline
\end{tabular}




\section{Microstructural evolution during cold rotary forging and after}

\section{heat-treatment}

\subsection{Optical microscopy analysis}

Although the optical images were collected from different locations of the asR sample (as shown in Figure 5), Figure 8 shows only two representative optical images as collected from both the asR cross-sections. The microstructure of the cross-section extracted from the centre (Figure 8a) contained equiaxed grains with diameters (in terms of equivalent circle diameter) ranging from $\sim 5-50 \mu \mathrm{m}$ with an average grain size of $\sim 31.6 \mu \mathrm{m}$. Apart from that a considerable amount of carbides and twins were also observed. In comparison to that, the crosssection extracted from the periphery (Figure 8b) showed substantially smaller equiaxed grains with an average grain size of $\sim 12.6 \mu \mathrm{m}$. As already mentioned in Section 3, this difference in grain size from the centre to the periphery of the core cylinder was expected, however the average grain size obtained from the periphery is of our main interest as it represents the grain size of the asR material before cold rotary forging.

(a) asR cross-section extracted from center

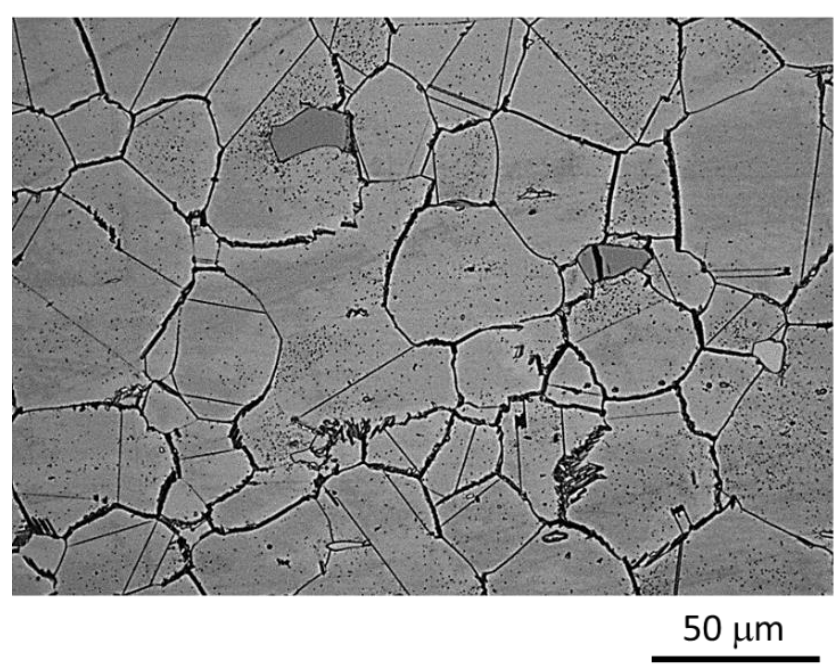

(b) asR cross-section extracted from periphery

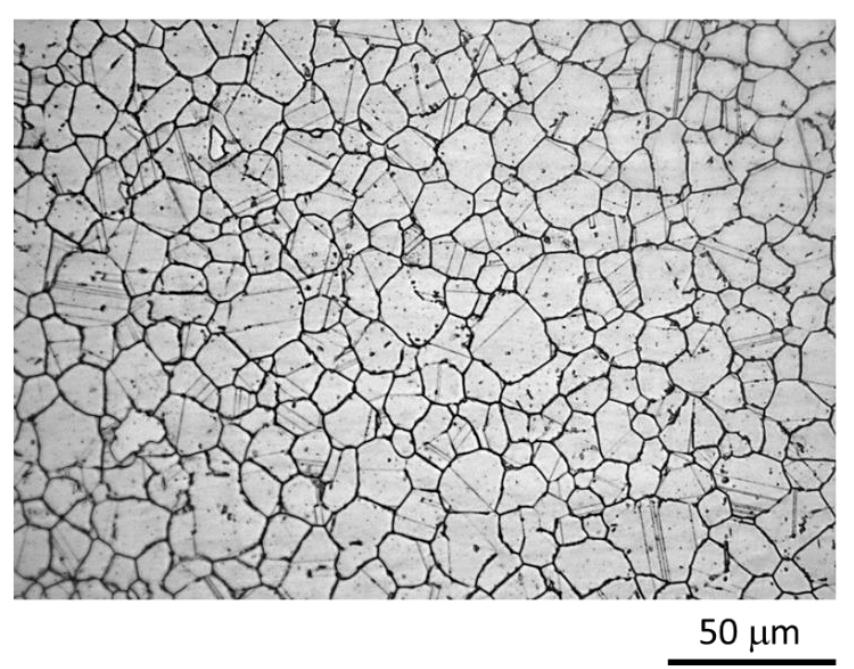

Figure 8: Representative optical images collected from asR cross-sections extracted - (a) from the centre and (b) from the periphery of the core cylinder

Figure 9 shows representative optical images collected from each section of the cold rotary forged (CF) IN718 samples. The images were collected from inside, middle and outside zones 
of each section in order to identify any variation in grain size and shape as a result of deformation during cold rotary forging process. Equiaxed grains and a lot of twins were observed in all three zones of sections 1, 3 and 4 (Figure 9a, Figure 9c and Figure 9d respectively), whereas section 2 exhibited elongated structure suggesting this particular section must have experienced higher level of strains due to the constraints of the rotary forging process. The process involved deforming the preform in a preferential direction to achieve the required flange, thus section 2 experienced highest deformation among all these four sections resulting in apparently two different regions of microstructure exhibiting elongated grains towards section1 and equiaxed grains towards section3 (as annotated in 'towards sec1' and 'towards sec3' of Figure 9b respectively). When 90 degree bend corners of section2 were examined (as annotated by the dotted line in 'along the bend' of Figure 9b), a significant change in the microstructure was observed from the bottom to the top corner. The bottom corner showed some disruption to the material flow resulting in formation of significantly large elongated grains (as shown in 'along the bend' of 'sec2 outside', Figure 9b) with a number of folds. On the other hand, completely equiaxed grains (as shown in 'along the bend' of 'sec2 inside', Figure 9b) with no evidence of material folds or cracks were observed at the top corner. The transition from the elongated to the equiaxed grain structure was evident at the middle of 90 degree bend (as shown in 'along the bend' of 'sec2 mid', Figure 9b). Overall, no significant variation in grain size and shape was observed in between three zones of each section except along the 90 degree bend of section2, however a considerable difference was noticed from one section to another.

Figure 10 shows representative optical images collected from each section of the cold rotary forged and heat-treated $(\mathrm{CF}+\mathrm{HT})$ IN718 samples. Similar to CF samples, the images were collected from inside, middle and outside zones of each section. Equiaxed grains and traces of carbides were observed in all three zones of $\mathrm{CF}+\mathrm{HT}$ sections 1, 3 and 4 but almost no twins were observed (Figure 10a, Figure 10c and Figure 10d respectively). It was described earlier that the $\mathrm{CF}$ section 2 contained two different types of microstructure consisting elongated grains towards section 1 and equiaxed grains towards section 3 with a microstructural transition along the 90 degree bend (Figure 9b), which was significantly changed after the heat-treatment. Most of the elongated grains towards section 1 of CF sample were transformed into equiaxed grains after heat-treatment (as shown in 'towards sec1' of Figure 10b), though few of the elongated grains were still present at the middle of section 2 rather than the periphery (inside or outside). Unlike CF section2, no microstructural transition along the 90 degree bend was observed after 
heat-treatment (as shown in 'along the bend' of Figure 10b). On the other hand, the equiaxed grains towards section 3 of the $\mathrm{CF}$ sample remained unaffected by the cold deformation leading to a homogeneous and equiaxed microstructure after the heat-treatment (as shown in 'towards sec3' of Figure 10b). From manufacturing point of view, a homogeneous microstructure is always preferred. 


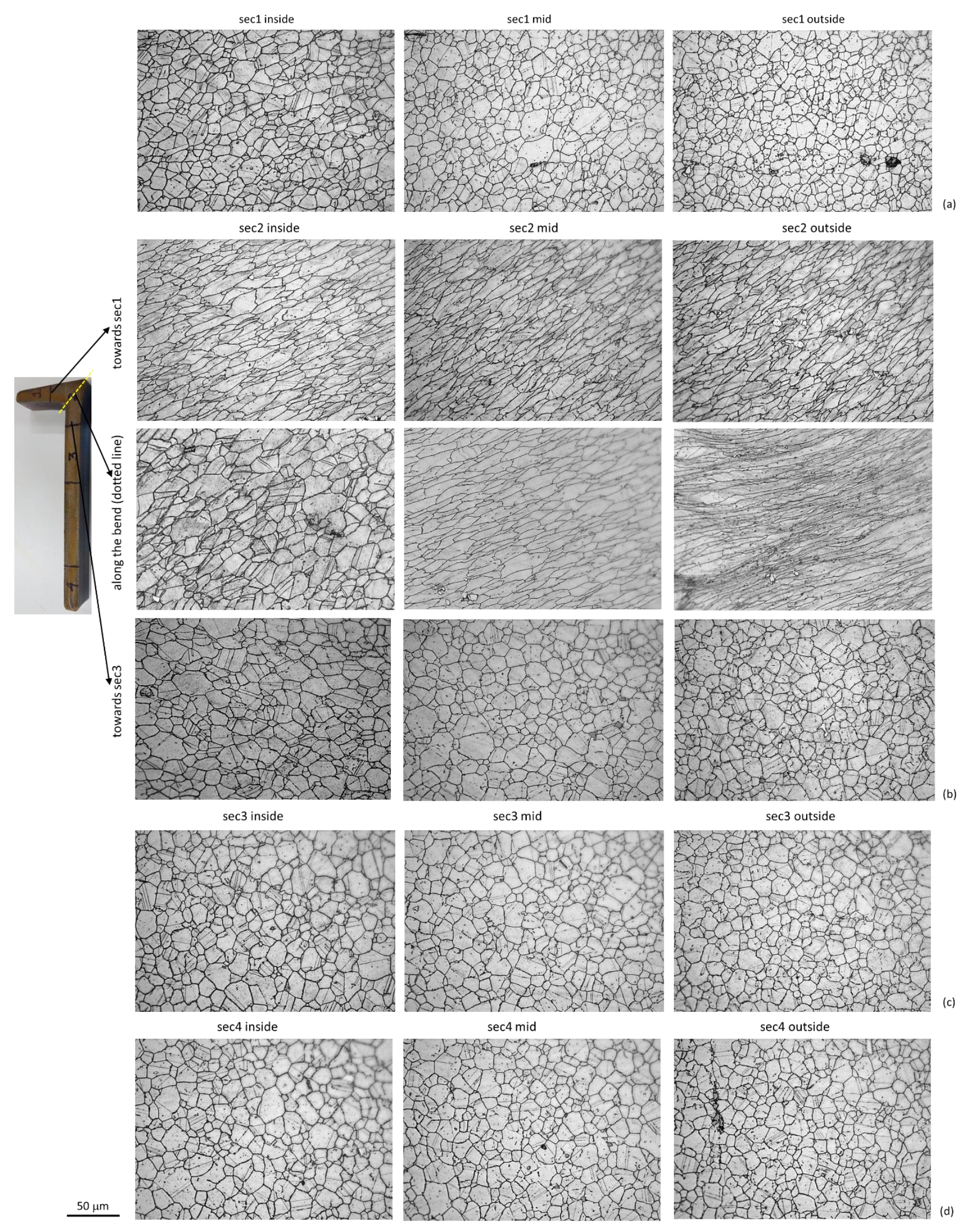

Figure 9: Representative optical images (at same magnification) collected from cold rotary

forged (CF) IN718 part - (a) section1, (b) section2, (c) section 3 and (d) section4 

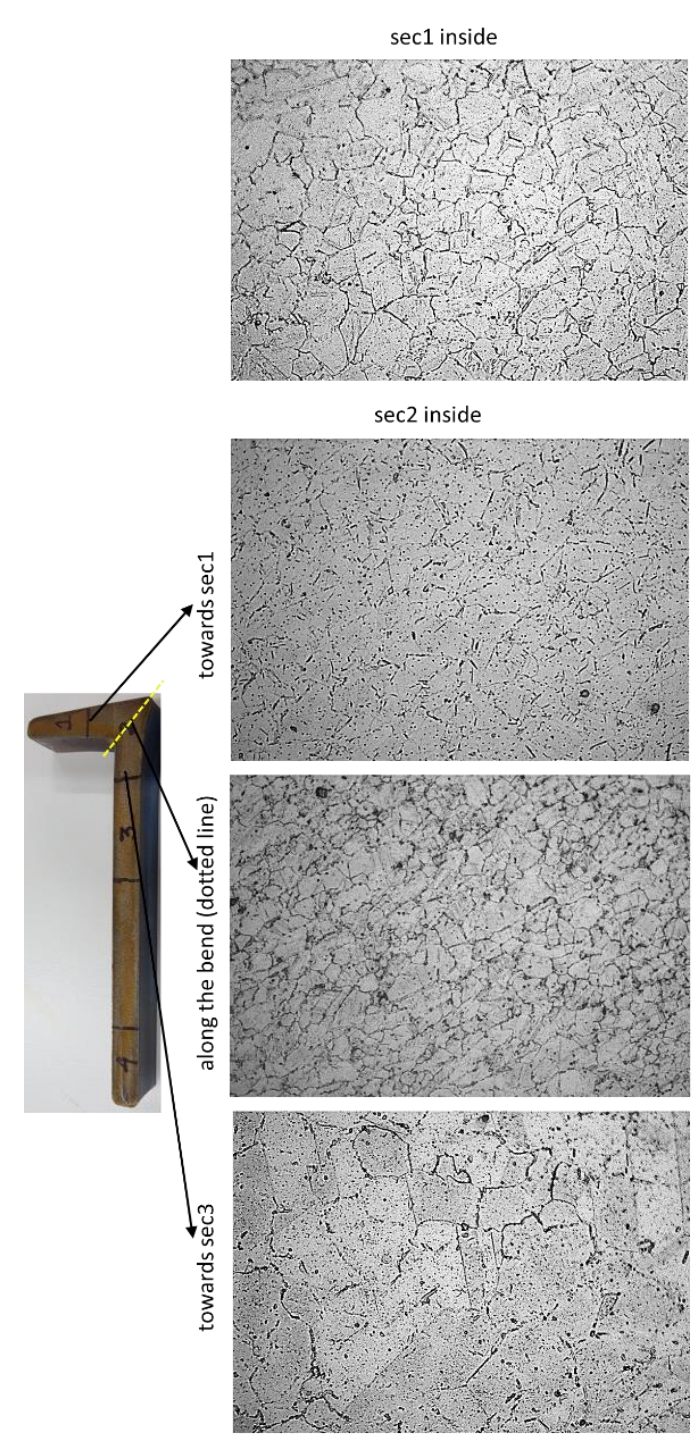

sec3 inside

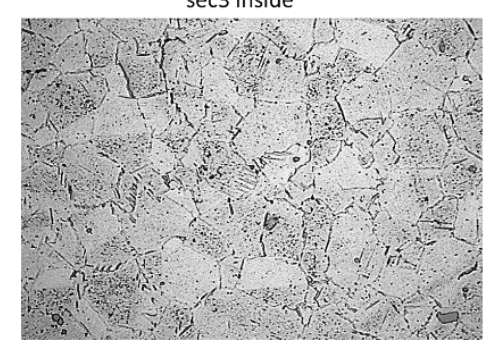

sec4 inside

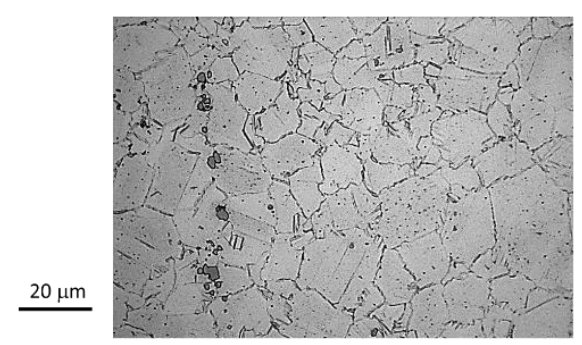

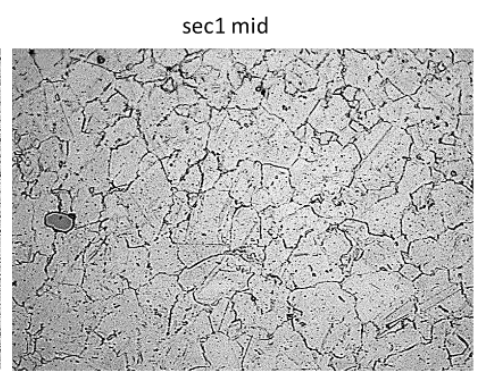

sec2 mid
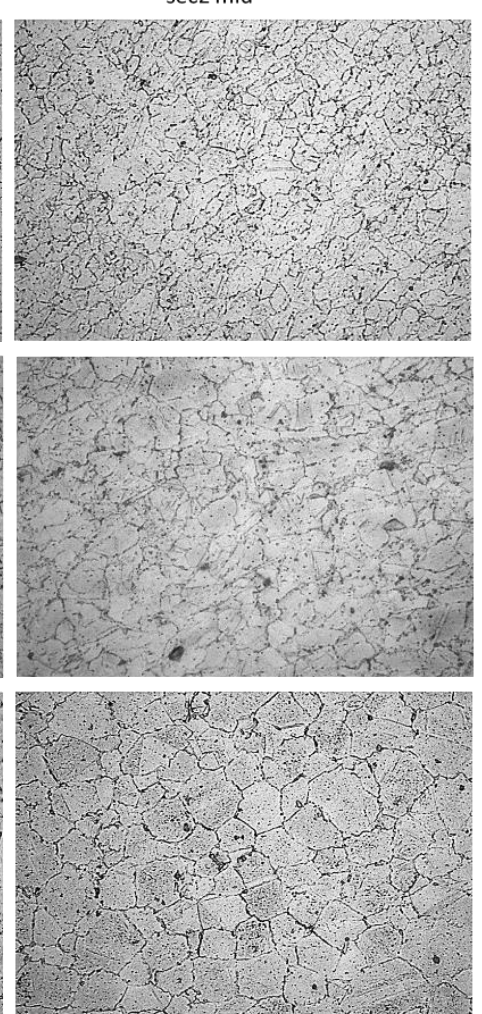

sec3 mid

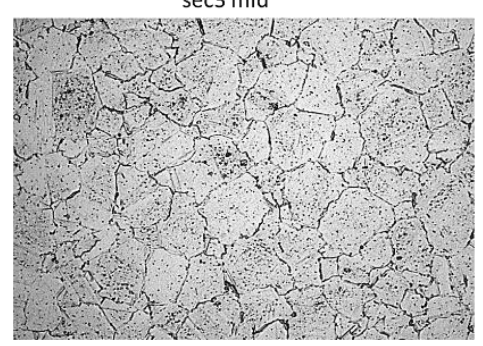

sec4 mid

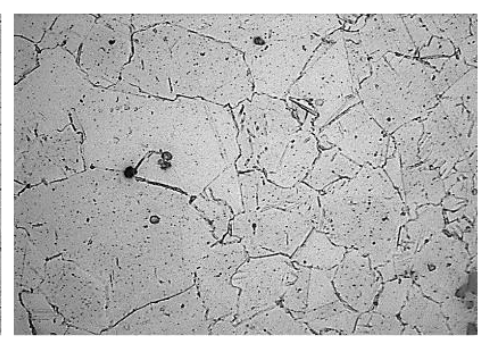

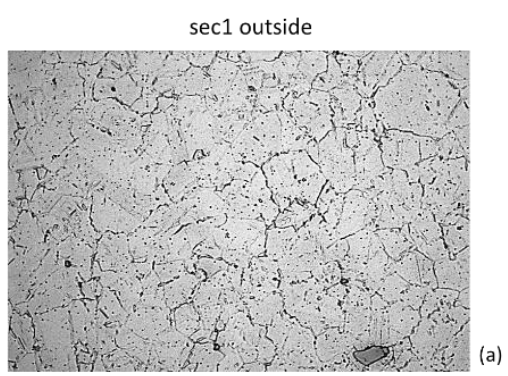

$\sec 2$ outside
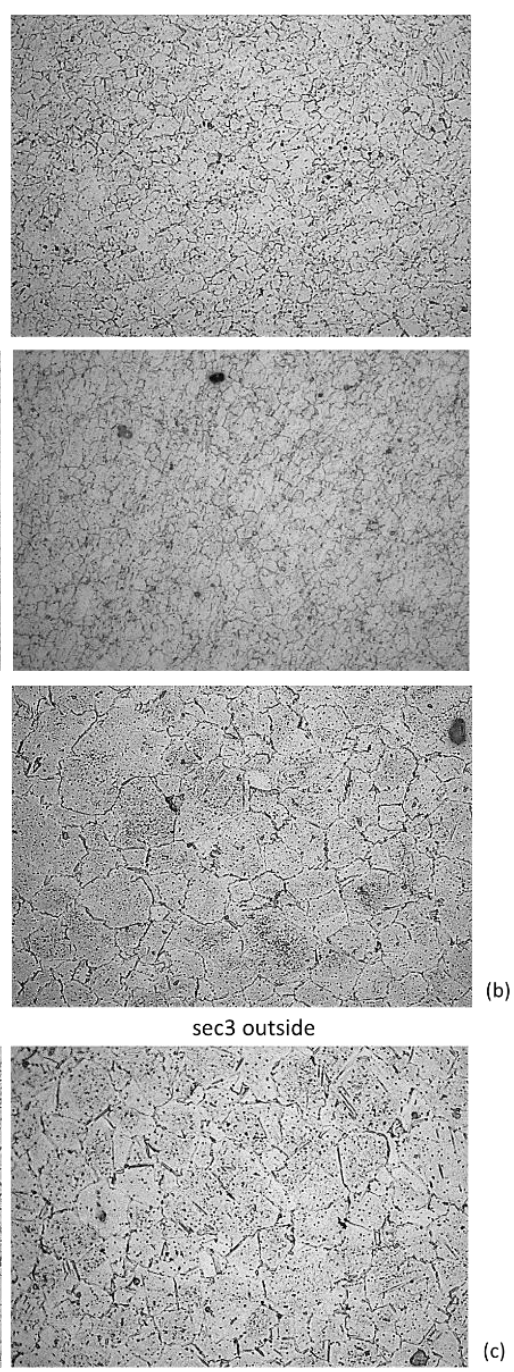

sec4 outside

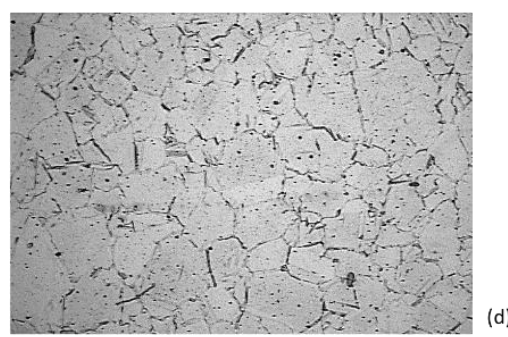

Figure 10: Representative optical images (at same magnification) collected from cold rotary forged and heat-treated (CF+HT) IN718 part - (a) section1, (b) section2, (c) section3 and (d) section4 
Figure 11 shows the summary of average grain size of asR, $\mathrm{CF}$ and $\mathrm{CF}+\mathrm{HT}$ sections as calculated from the optical micrographs. A significant difference was observed in the average grain size of the asR material from the centre $(\sim 31.65 \mu \mathrm{m})$ to the periphery $(\sim 12.6 \mu \mathrm{m})$ of the core cylinder, but the later one was of our main interest. No noticeable grain refinement was observed after the cold rotary forging, although a slight difference in the average grain size was observed between section1 $(\sim 10.07 \mu \mathrm{m})$ and other three sections $(\sim 12.34-12.76 \mu \mathrm{m})$ of the CF part. The heat-treatment applied on the cold rotary forged part showed no noticeable grain refinement as compared to the as $\mathrm{R}$ material or the $\mathrm{CF}$ part, but neutralised the difference in average grain sizes of the four CF sections by imparting a homogeneous and equiaxed microstructure throughout the heat-treated flange (an average grain size of $\sim 11.36-12.01 \mu \mathrm{m}$ ). Formation of this homogeneous microstructure clearly indicated the efficiency of cold rotary forging process and the selected heat-treatment. It should be noted that the average grain size of $\mathrm{CF}$ section2 was decreased after the heat-treatment as per our expectation, however the standard deviation value was significantly increased in $\mathrm{CF}+\mathrm{HT}$ section2 due to the formation of very fine grains as a result of the heat-treatment within the severely deformed 90 degree bend zone. This change in microstructure, particularly in the middle of the severely deformed zone, was further investigated by the EBSD analysis.

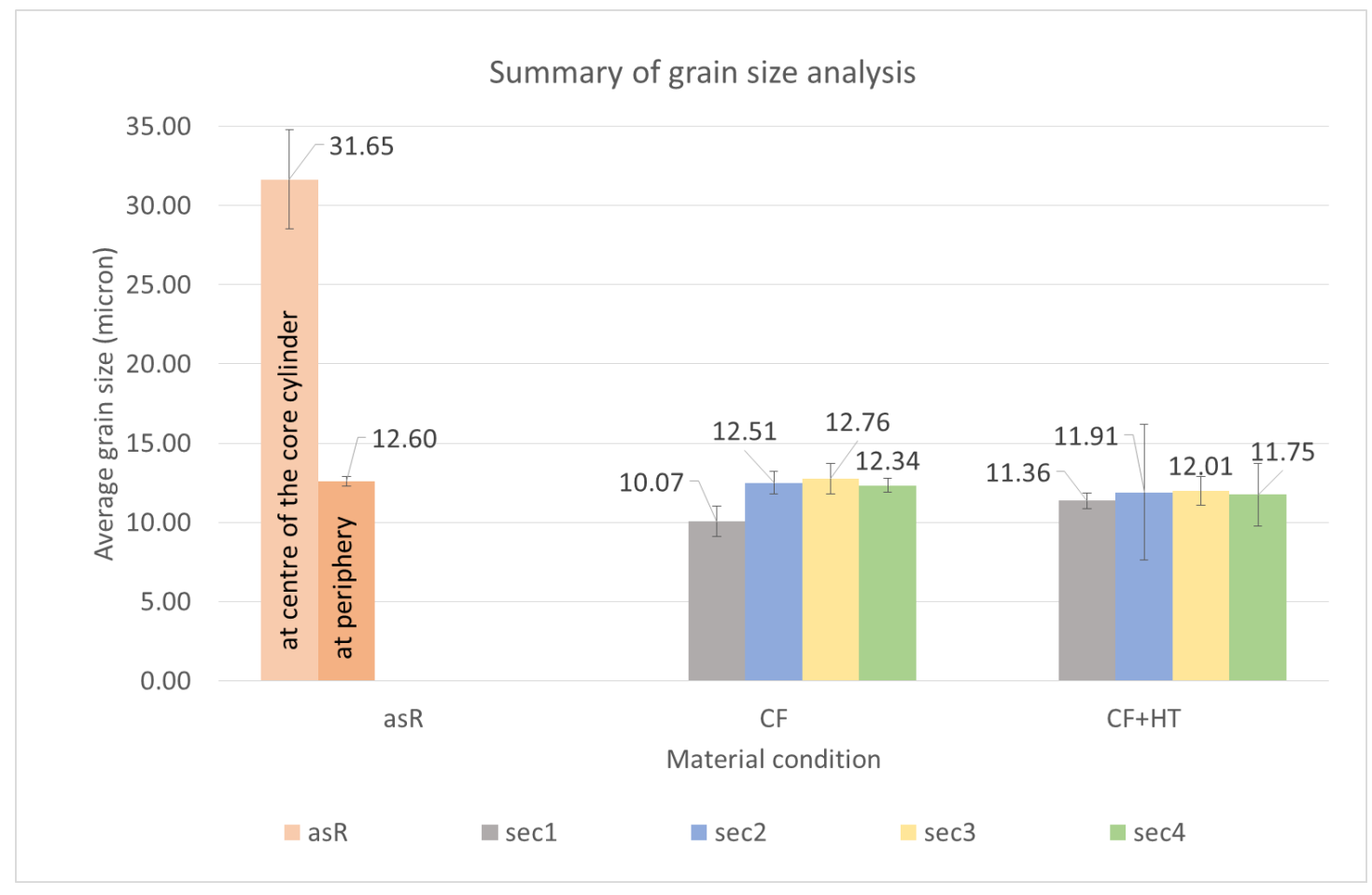

Figure 11: Summary of average grain size of as $R, C F$ and $C F+H T$ sections 


\subsection{EBSD analysis}

In order to understand the microstructural changes from as-received condition to severely deformed condition (observed exactly at the middle of severely deformed 90 degree bend zone in both $\mathrm{CF}$ section 2 and $\mathrm{CF}+\mathrm{HT}$ section2) as imposed by both cold rotary forging and postforging heat-treatment, three samples, i.e. asR cross-section (extracted from the periphery), $\mathrm{CF}$ section2 and $\mathrm{CF}+\mathrm{HT}$ section2, were further subjected to EBSD analysis. The EBSD analysis covers the microstructural changes in terms of change in grain size and shape, grain orientation, area fraction of grains, average misorientation and evolution of crystallographic texture. Here it should be noted that the grain sizes obtained from the EBSD analysis of both CF section2 and $\mathrm{CF}+\mathrm{HT}$ section 2 are different than that obtained from the optical micrographs (Figure 11). The reason is that the optical micrographs represent the average grain size of the entire section2, whereas the EBSD analysis particularly indicates the size of very fine grains within the severely deformed 90 degree bend zone rather than the entire section2. Thus grain size distribution obtained from EBSD analysis is not representative of the entire section2 and therefore cannot be directly compared with the results from optical micrographs as presented above.

Figure 12 shows the band contrast (BC) images and phase maps of asR cross-section and the middle of 90 degree bend zones in both $\mathrm{CF}$ section 2 and $\mathrm{CF}+\mathrm{HT}$ section2. In all three samples, Ni FCC (indicated in yellow) was observed as the main phase. The asR cross-section showed presence of equiaxed grains with a lot of twins in it. At the middle of 90 degree bend zone in CF section2, the grains were elongated along the deformation direction due to severe amount of cold working leading to a considerable reduction in grain size when compared to the asR condition. The twins were still observed in $\mathrm{CF}$ section 2 similar to asR condition. After the heattreatment, the elongated grains were significantly refined and the twins were disappeared from the middle of 90 degree bend zone in $\mathrm{CF}+\mathrm{HT}$ section2. This grain refinement due to severe cold working was further evident from Figure 13, which showed the grain size distribution (in terms of equivalent circle diameter) of all three samples. In the asR material, most of the grains were found within $5-35 \mu \mathrm{m}$ diameter range, however very few grains were observed as large as $50 \mu \mathrm{m}$ leading to an average grain size of $10.9 \pm 6.77 \mu \mathrm{m}$. This supports the observations obtained from optical micrographs (Figure 8b and Figure 11). Cold rotary forging caused severe deformation in the 90 degree bend zone of section 2 resulting in formation of refined but elongated grains. This behaviour can be explained with the grain refinement theory during the 
first pass of an Equal Channel Angular Pressing (ECAP) process. ECAP involves repetitive passes in which the material billet is pressed in a typically 90 degree bend channel and thus the orientation of the billet microstructure changes with each pass. This process produces a uniform shear throughout the bulk material but results in very high strains. Therefore the first pass of an ECAP process is similar to the current cold rotary forging process as both processes involve material flow in a 90 degree bend channel resulting in high deformation. The EBSD study of ECAP process demonstrates that the grain refinement occurs progressively with each pass towards the deformation direction. Chrominski et al. [21] reported that in simple materials, such as pure Aluminium, the first pass of ECAP led to formation of a deformation band with elongated grains in it and then the grain refinement was occurred through formation of transverse boundaries in the favourably oriented grains. As a result, the misorientation angle distribution was dominated by the low angle grain boundaries (LAGB) rather than high angle grain boundaries (HAGB) after the first pass. Due to the similarities present in the first pass of ECAP process and the cold rotary forging of a 90 degree bend flange (in current work) with regards to process dynamics, the grain refinement observed in the current work can be best described based on the observations reported for the ECAP process. This could explain why the 90 degree bend zone of CF section2 exhibited refined grains mostly within $2-25 \mu \mathrm{m}$ diameter range leading to an average grain size of $6.51 \pm 3.95 \mu \mathrm{m}$. The heat-treatment following cold rotary forging, resulted in recrystallization of the CF section2 leading to significant refinement of grains within the diameter range of $1-8 \mu \mathrm{m}$. Thus the middle of 90 degree bend zone in $\mathrm{CF}+\mathrm{HT}$ section2 showed an average grain size of $3.62 \pm 1.11 \mu \mathrm{m}$.

When the crystallographic orientation of these deformed grains was considered, no significant change was observed from the asR condition. Figure 14 compares the inverse pole figure (IPF) maps generated from asR cross-section and the middle of 90 degree bend zones in both $\mathrm{CF}$ section 2 and $\mathrm{CF}+\mathrm{HT}$ section2. The axial and transverse directions (AD and TD respectively) of a representative section are displayed on the bottom of the IPF maps. The image at the left hand side is the band contrast (BC) image for which the IPF maps are generated (in the right side of the corresponding BC image). The IPF maps showed random orientation of grains in asR condition that was retained after cold rotary forging as well as after the heat-treatment. Therefore the cold rotary forging and corresponding heat-treatment significantly refined the microstructure of the severely deformed 90 degree bend zone but did not influence the grain orientation. 

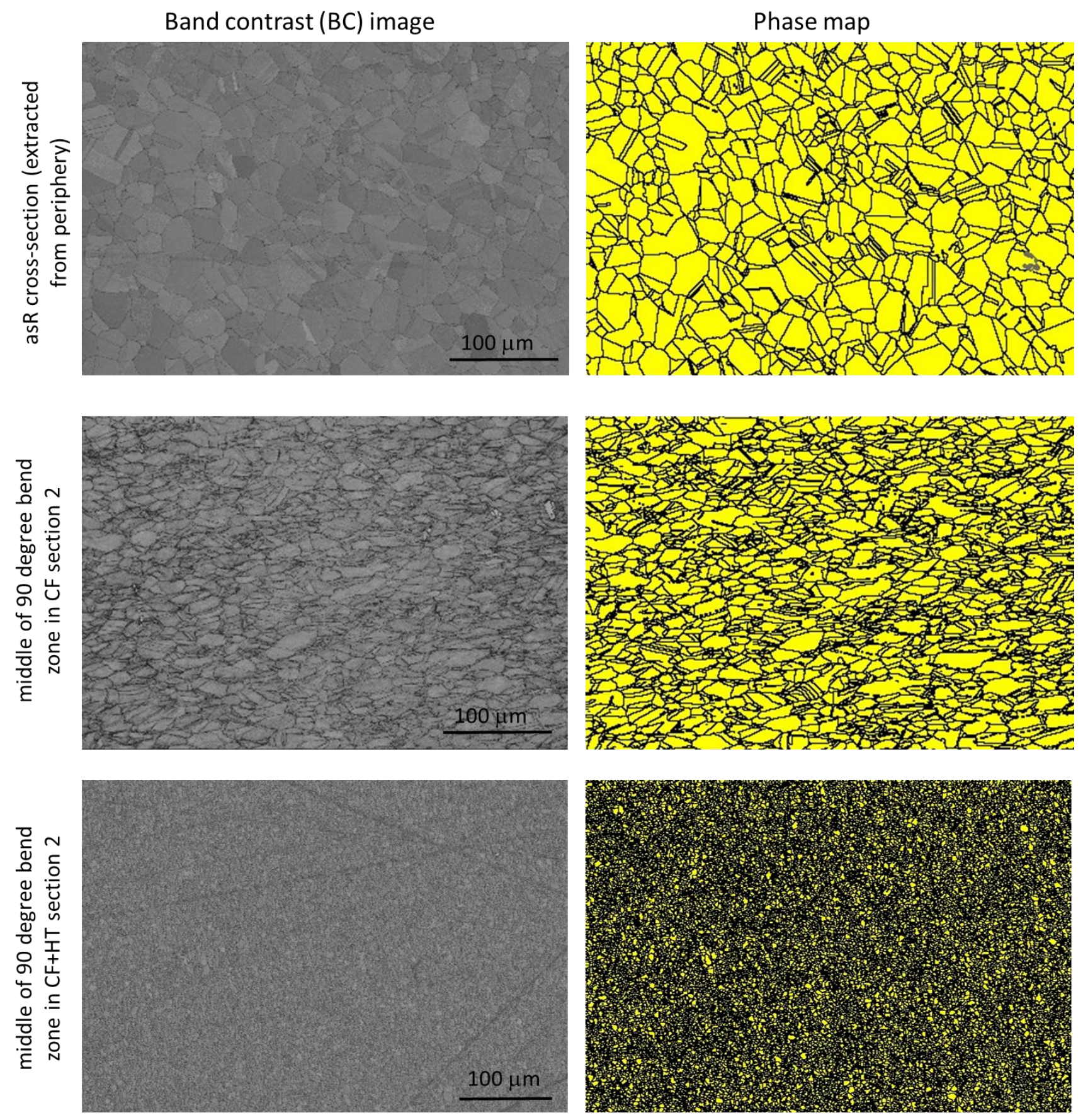

Figure 12: Band contrast (BC) images and phase maps (yellow indicates Ni FCC phase) showing the microstructure evolution of asR cross-section and middle of 90 degree bend zone in both $C F$ section 2 and $C F+H T$ section 2 

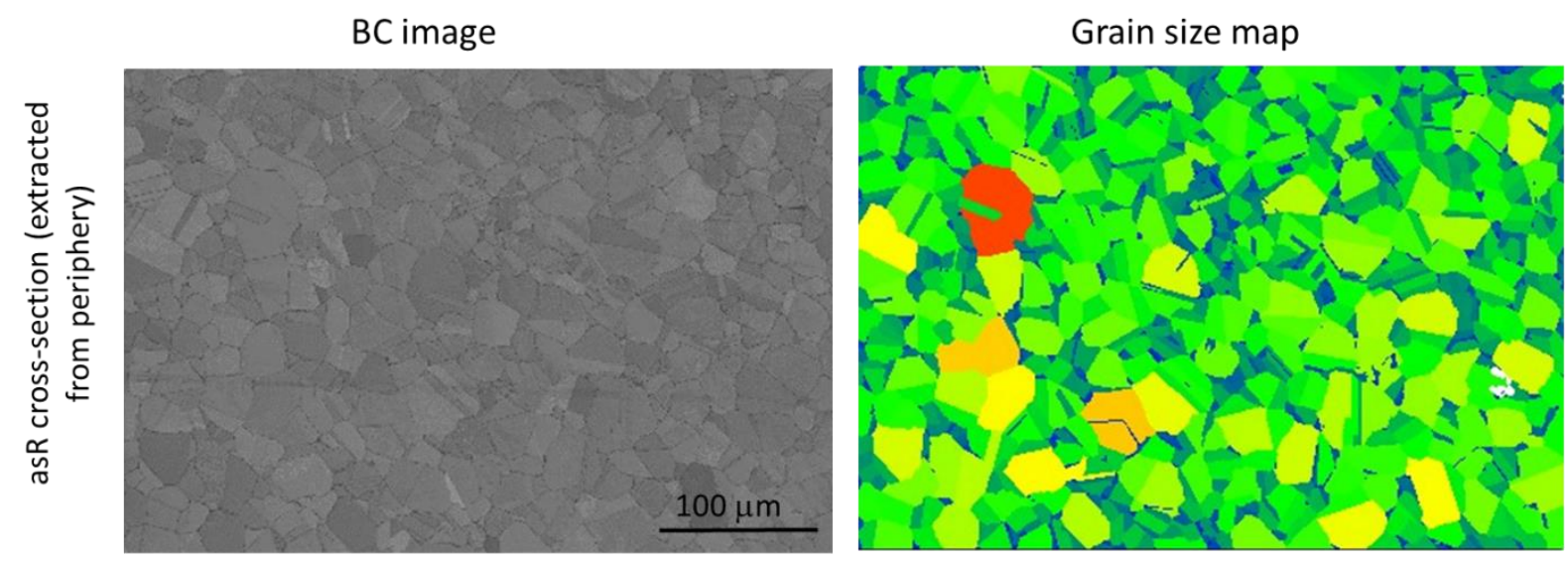

Average grain size: $10.9 \pm 6.77 \mu \mathrm{m}$

$\begin{array}{lllllllllllllllllllllllll}2 & 4 & 6 & 8 & 10 & 12 & 14 & 16 & 18 & 20 & 22 & 24 & 26 & 28 & 30 & 32 & 34 & 36 & 38 & 40 & 42 & 44 & 46 & 48 & 50\end{array}$

Equivalent circle diameter $(\mu \mathrm{m})$
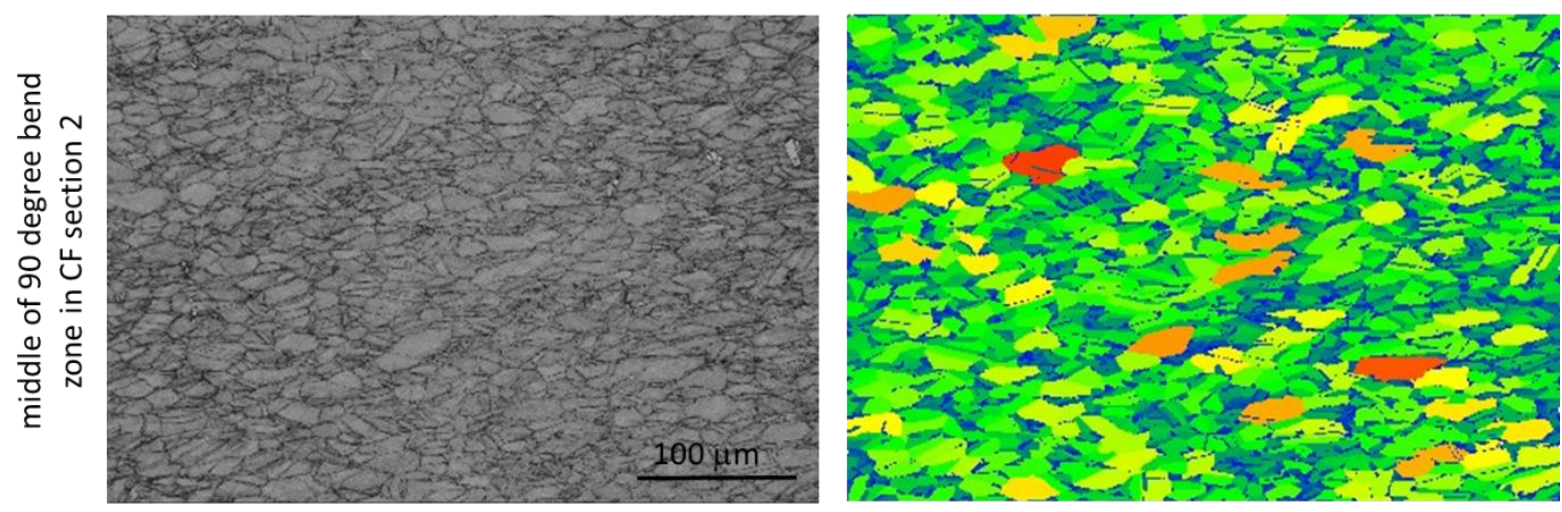

Average grain size: $6.51 \pm 3.95 \mu \mathrm{m}$

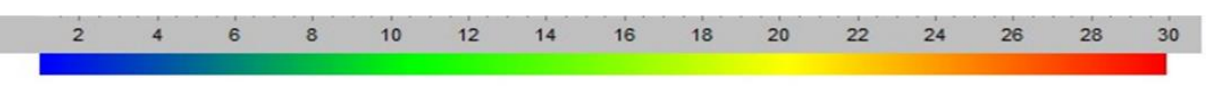

Equivalent circle diameter $(\mu \mathrm{m})$
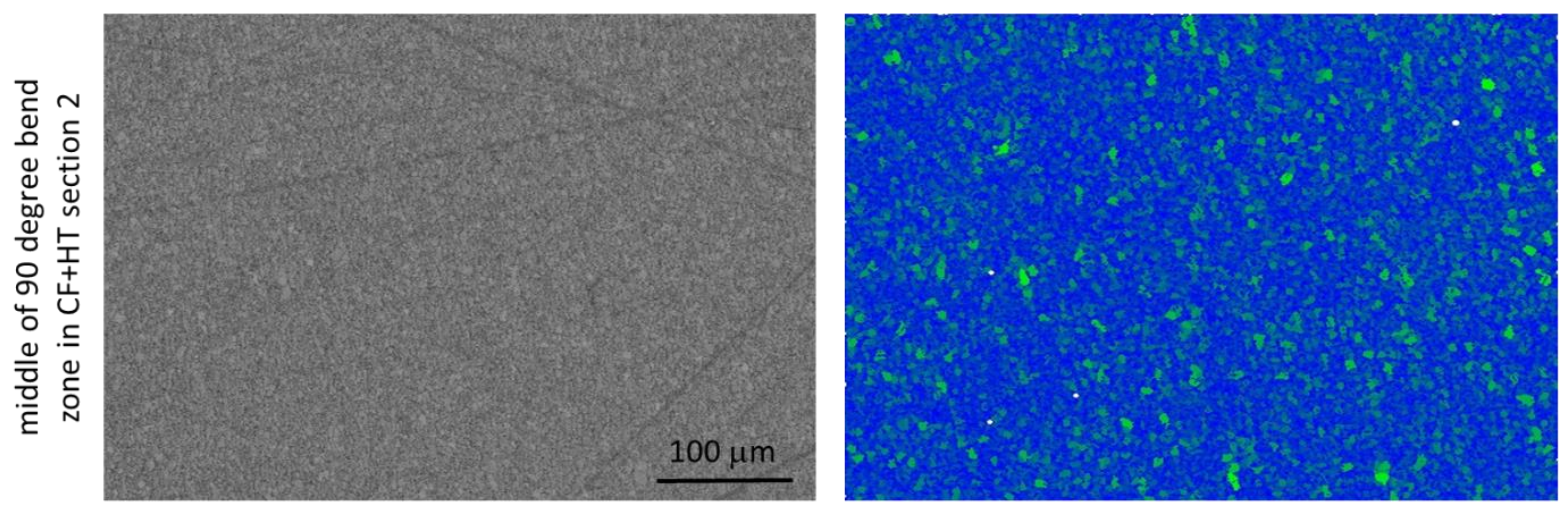

Average grain size: $3.62 \pm 1.11 \mu \mathrm{m}$

$\begin{array}{lllllllllllllll}2 & 4 & 6 & 8 & 10 & 12 & 14 & 16 & 18 & 20 & 22 & 24 & 26 & 28 & 30\end{array}$

Equivalent circle diameter $(\mu \mathrm{m})$

Figure 13: Grain size distribution showing the microstructure evolution of as $R$ cross-section and middle of 90 degree bend zone in both $C F$ section 2 and $C F+H T$ section 2 

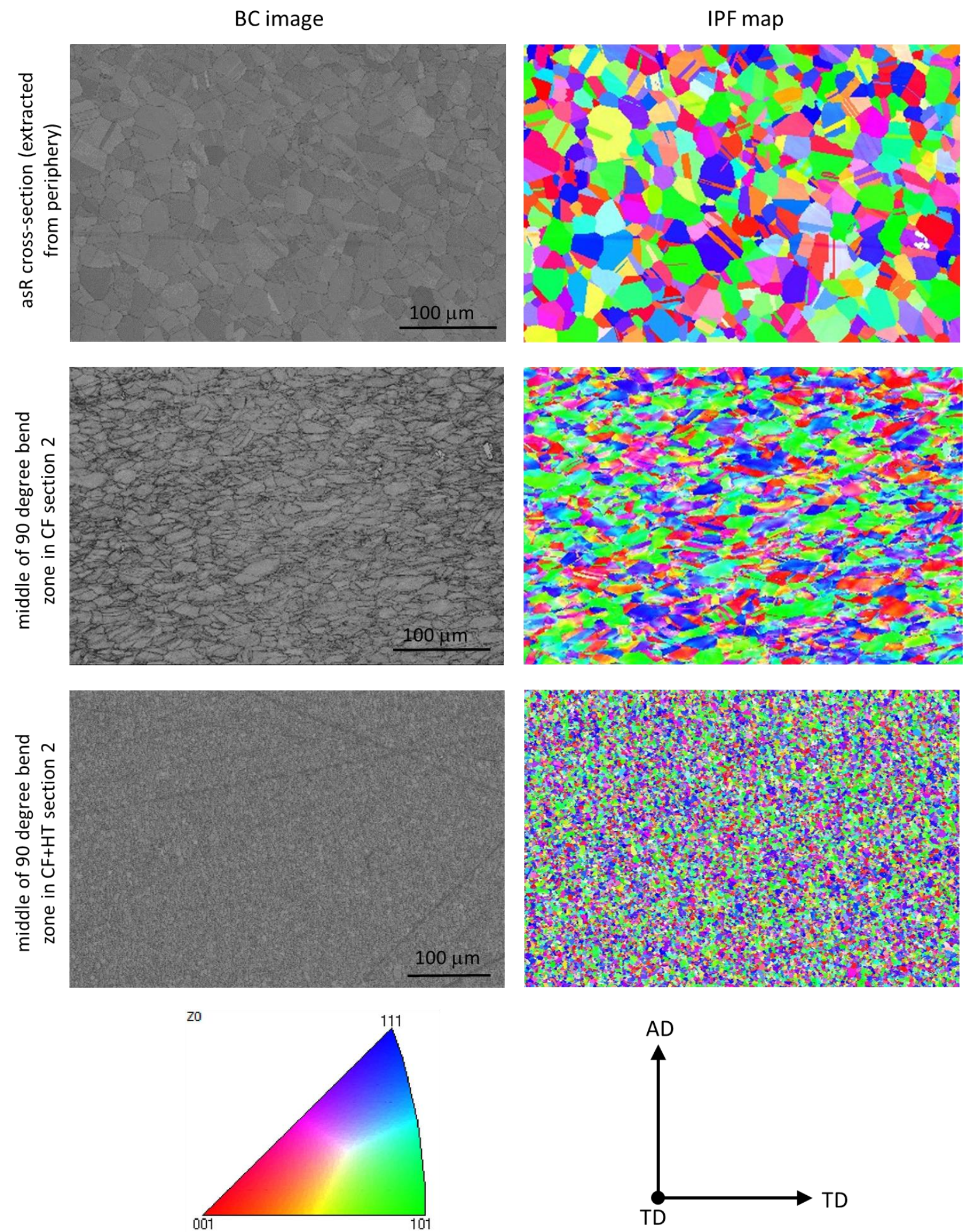

Figure 14: A comparison of IPF maps showing the microstructure evolution of asR crosssection and middle of 90 degree bend zone in both $C F$ section 2 and $C F+H T$ section 2 
Figure 15 shows the area fraction of recrystallized, sub-structured and deformed grains present in the asR cross-section and the middle of 90 degree bend zones in both CF section 2 and $\mathrm{CF}+\mathrm{HT}$ section2. The recrystallized, sub-structured and deformed grains are shown in blue, yellow and red colours respectively in the area fraction maps and summary graph. The deformed grains contain large number of dislocations and are defined by the misorientation angle equal to or lower than $5^{\circ}$. The recrystallized grains are the undeformed grains that do not contain stored elastic energy and are defined by a misorientation angle equal to or larger than $15^{\circ}$. The sub-structured grains are the metastable grains having a fewer number of dislocations and are defined by the misorientation angle ranging from $5^{\circ}$ to $15^{\circ}$. As observed from the summary graph of Figure 15, the asR material contained mainly recrystallized grains (94\%) and a little amount of sub-structured grains (5.94\%) as a result of solution treatment. Cold rotary forging imparted severe deformation in the 90 degree bend zone of section2, thus the amount of sub-structured and deformed grains were increased significantly (36\% and $55.5 \%$ respectively). The increase in amount of sub-structured grains indicated the subdivision of elongated grains due to severe cold working resulting in considerable grain refinement. The heat-treatment was applied on the cold rotary forged part to impart adequate ductility and toughness. As a result most of the severely deformed grains in the 90 degree bend zone of $\mathrm{CF}+\mathrm{HT}$ section2 were recrystallized (67.9\%) and subsequently the amount of sub-structured and deformed grains $(27.1 \%$ and $5.04 \%$ respectively) were decreased when compared to the CF condition.

Figure 16 shows the KAM maps exhibiting the strain distribution at the middle of 90 degree bend zone in both $\mathrm{CF}$ section 2 and $\mathrm{CF}+\mathrm{HT}$ section2. The cold rotary forging results in severe deformation in the 90 degree bend zone, thereby increasing the number of dislocations. The strain is a manifestation of these dislocations generated due to the deformation. Wright et al. [22] reviewed different strain analysis techniques using EBSD and particularly focussed on the local misorientation approach for measuring the plastic strain. KAM map measures the local misorientations between individual measurement points and thereby represents the strain of the scanned area. The red and blue colours respectively denote the highest and lowest levels of misorientations for these scanned areas as shown in the scale bar. As observed, the deformation present in the CF section 2 resulted in high level of misorientation (denoted by red and yellow colours), whereas recrystallization during heat-treatment annihilated the dislocations leading to significantly low level of misorientations (denoted by blue and green colours) in $\mathrm{CF}+\mathrm{HT}$ section2. It is important to note that the KAM map is so sensitive towards the strain difference 
between two neighbouring points (i.e. misorientation difference), that it can clearly differentiate the scratches generated during polishing steps as highly strained area (denoted by mainly yellow colour with few red points) from rest of the area in CF+HT section2.

These results further indicate that the strain levels in the most deformed CF section 2 and $\mathrm{CF}+\mathrm{HT}$ section 2 can be correlated with their respective average grain size and with the area fraction of grains. Figure 13 shows the grain refinement of asR material after cold rotary forging, which can be attributed to the increase in the extent of deformation, as seen from the increased area fraction of sub-structured and deformed grains in Figure 15. The deformation imparted by the cold rotary forging process causes grain refinement (average grain size of 6.51 $\pm 3.95 \mu \mathrm{m}$ ) through increase in dislocation density and formation of sub-structured grains. The post-forging heat-treatment causes recrystallization leading to strain-free microstructure (i.e. decrease in deformation) consisting of finer recrystallized grains (average grain size of $3.62 \pm$ $1.11 \mu \mathrm{m})$. Figure 16 further substantiates the fact about decrease of the extent of deformation (i.e. plastic strain) due to post-forging heat-treatment. The KAM maps clearly show that the CF section 2 exhibit much higher level of average misorientation, hence strain, as compared to that observed in $\mathrm{CF}+\mathrm{HT}$ section2. Thus, the change in strain level throughout the processing steps clearly affects the grain size of the material from the asR to the post-forging heat-treated $(\mathrm{CF}+\mathrm{HT})$ conditions. 

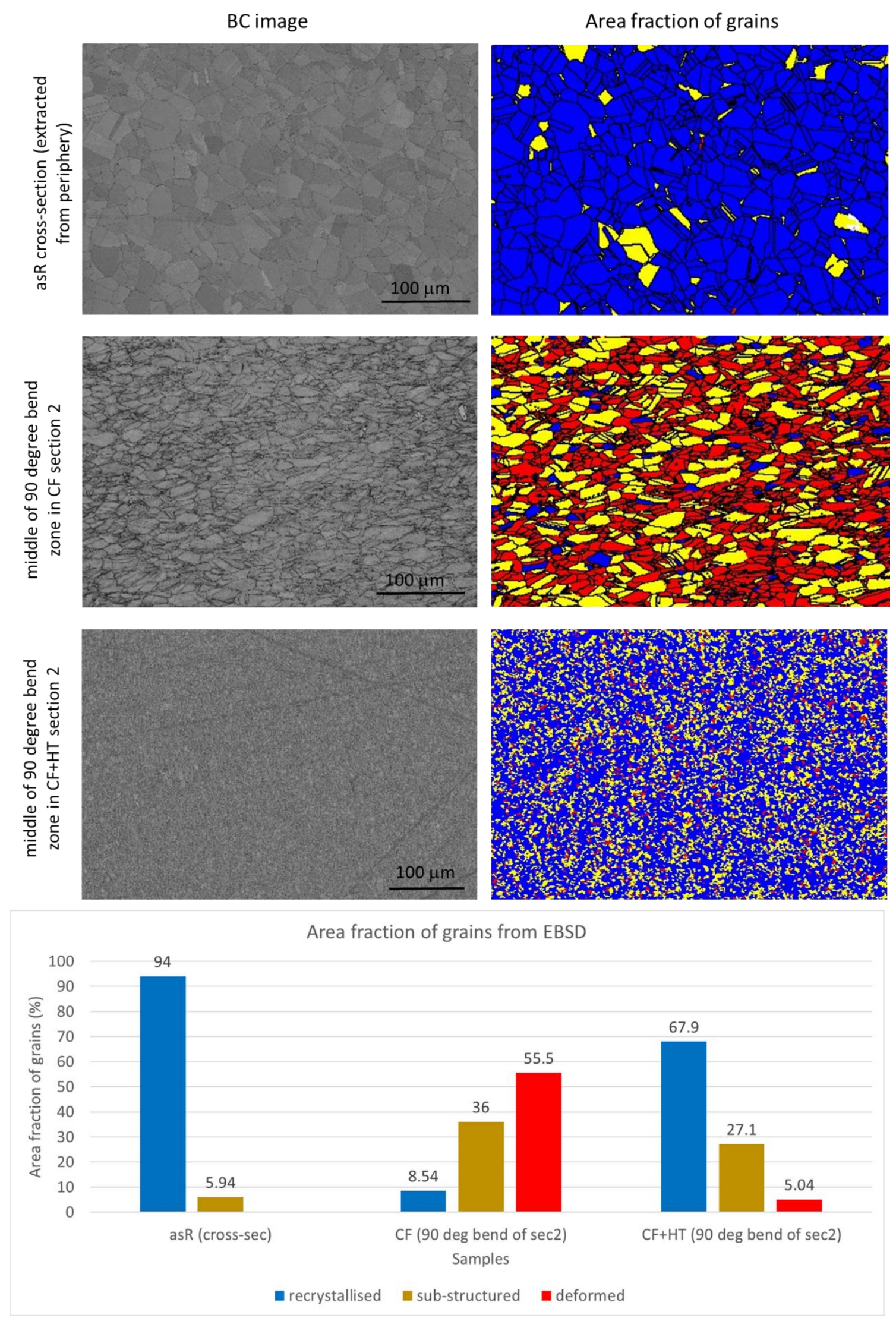

Figure 15: Area fraction of grains showing the microstructure evolution of asR cross-section and middle of 90 degree bend zone in both $C F$ section 2 and $C F+H T$ section 2 

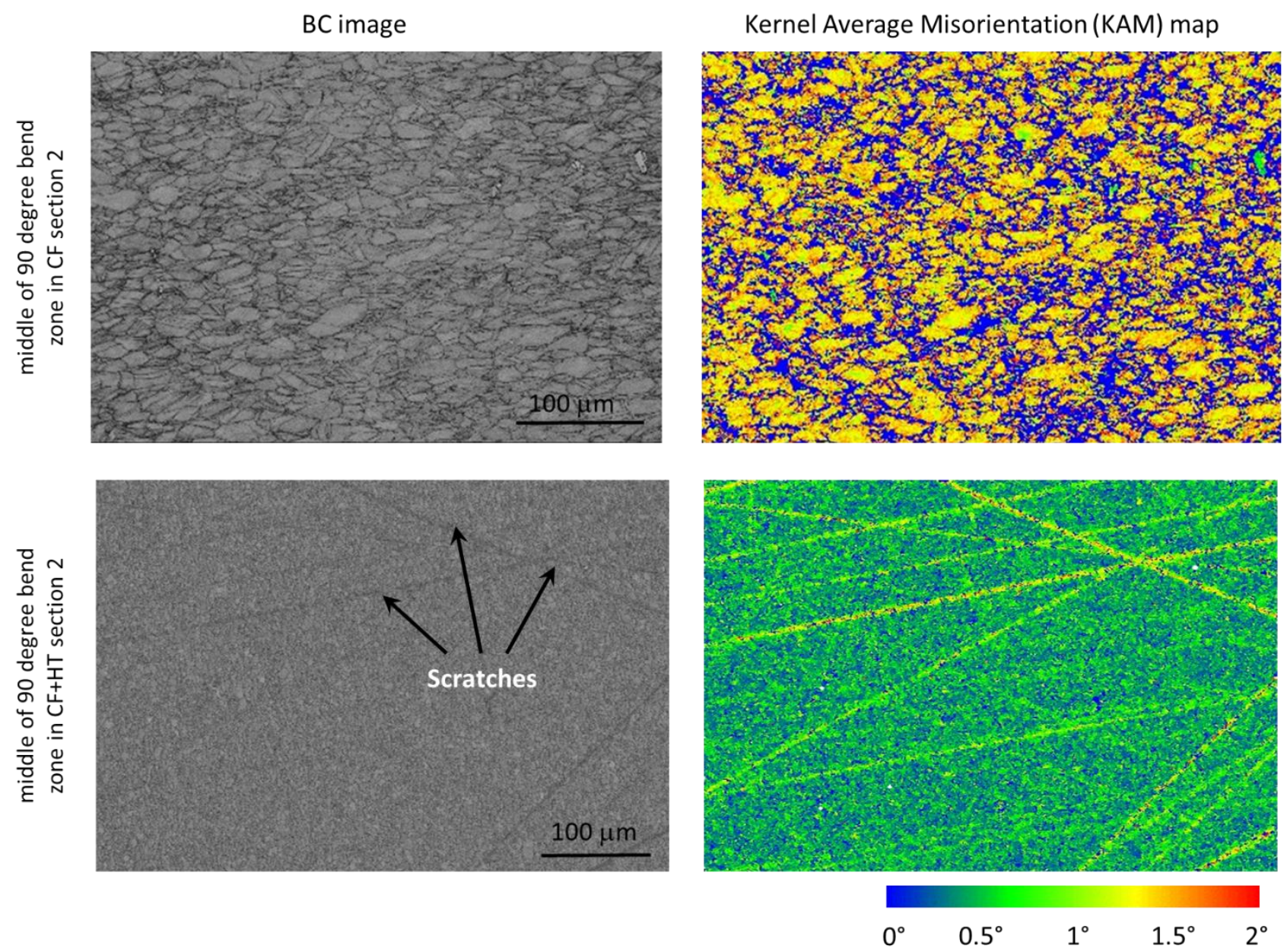

Figure 16: Kernel Average Misorientation (KAM) maps representing the strain distribution at the middle of 90 degree bend zone in both $C F$ section 2 and $C F+H T$ section 2

The evolution of crystallographic texture in the flange part during various stages of cold rotary forging process is noteworthy. Figure 17a shows the main texture fibres of FCC material as embedded in the reduced Euler's space. Suwas and Ray [23] and Wenk and Houtte [24] summarised that only a sub-volume of Euler's space (with $0 \leq \phi 1, \Phi, \phi 2 \leq 90^{\circ}$, where $\Phi, \phi 1$ and $\phi 2$ are three Euler angles as denoted by the Bunge notation) was required to represent the entire texture because of the cubic crystal symmetry of FCC materials. The important orientations of the rolling textures of FCC materials were generally appeared in the $\phi 2$ sections and the most important ODF sections were $\phi 2=45^{\circ}, 65^{\circ}$ and $90^{\circ}$ respectively. Kestens and Pirgazi [25] demonstrated the characteristics fibre components of FCC materials in $\phi 2=45^{\circ}, 65^{\circ}$ and $90^{\circ}$ sections and mentioned related dominant slip and twinning systems as $\{111\}<110>$ and $\{111\}$ <112> respectively, which has been reproduced in Figure 17b. Figure 17c lists the nomenclature and orientation of main texture fibres of FCC material, such as $\alpha$-fibre (110 $\|$ 
ND) connecting Brass and Goss components, $\gamma$-fibre (111 || ND) and $\tau$-fibre (110 || TD). The $\beta$-fibre, as shown in Figure $17 \mathrm{a}$, is not a fibre in true sense but connects copper and brass components.

Stacking fault energy (SFE) plays an important role in determining the mechanisms of plastic deformation. Kestens and Pirgazi [25] mentioned that materials with high SFE (such as aluminium and copper) showed strong presence of copper, brass and $\mathrm{S}$ texture components with equal intensities as slip was the dominant deformation mode for them. On the other hand, materials with low SFE (such as brass, austenitic stainless steel) exhibited both mechanical twinning and dislocation glide during plastic deformation, thus their rolling texture was composed of a strong brass component and a minor Goss orientation. The SFE was dependant on the amount of solute atoms and therefore influenced the texture of alloy systems. Chen et al. [26] mentioned IN718 as a low SFE alloy, which contained numerous solute atoms and precipitates that in turn restricted the cross-slip and mobility of dislocations. When mechanical twinning is accompanied by slip, a significant difference in texture is observed from the rolling texture.

Figure 18 shows evolution of ODF maps at $\phi 2=45^{\circ}, 65^{\circ}$ and $90^{\circ}$ sections collected from asR cross-section and the middle of 90 degree bend zones in both $\mathrm{CF}$ section 2 and $\mathrm{CF}+\mathrm{HT}$ section 2 . The asR material showed presence of both Brass and Goss components at $\phi 2=45^{\circ}$ and $90^{\circ}$ sections, and a weak $\mathrm{S}$ texture component at $\phi 2=65^{\circ}$ section. It should be noted that the FCC material's characteristics fibres weren't evident in the asR material. Cold rotary forging reduced number of twins due to strain hardening when compared to the as-received condition (Figure 8 and Figure 9). As a result, the fibre-type texture was appeared in the middle of 90 degree bend zone of CF section2, which was completely absent in asR condition. The $\tau$-fibre was appeared at $\phi 2=45^{\circ}$ section and both the Brass and $S$ texture components (at $\phi 2=45^{\circ}$ and $65^{\circ}$ sections respectively) became much stronger as compared to the asR material. The heattreatment eliminated the twins from the middle of 90 degree bend zone in $\mathrm{CF}+\mathrm{HT}$ section2 (Figure 10) showing another substantial change to the texture of $\mathrm{CF}+\mathrm{HT}$ section as compared to $\mathrm{CF}$ section. The locations of both $\tau$-fibre and $\mathrm{S}$ texture component (at $\phi 2=45^{\circ}$ and $65^{\circ}$ sections respectively) in $\mathrm{CF}+\mathrm{HT}$ section 2 were shifted towards left as compared to $\mathrm{CF}$ section2 and a strong Brass component was appeared at $\phi 2=90^{\circ}$ section. Overall, the texture was evolved at every step in the manufacturing process showing individual influence of cold rotary forging and related heat-treatment. When texture strength was considered, no significant difference 
was observed before and after cold rotary forging (maximum intensities of the asR and CF sections were found as 3.97 and 4.03 respectively), however the texture strength was slightly dropped after heat-treatment (maximum intensity of the $\mathrm{CF}+\mathrm{HT}$ section was 2.86).

G: Goss

B: Brass

C: Copper

D: Dillamore

S: "S" component

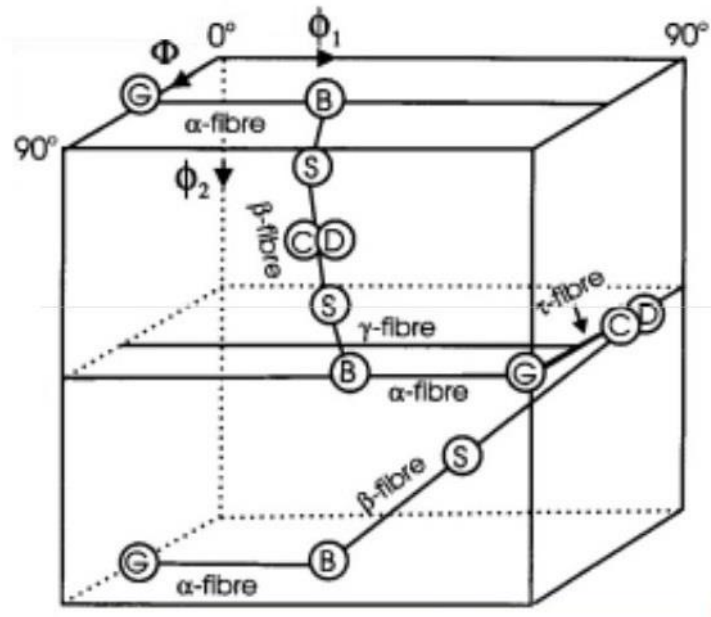

(a)
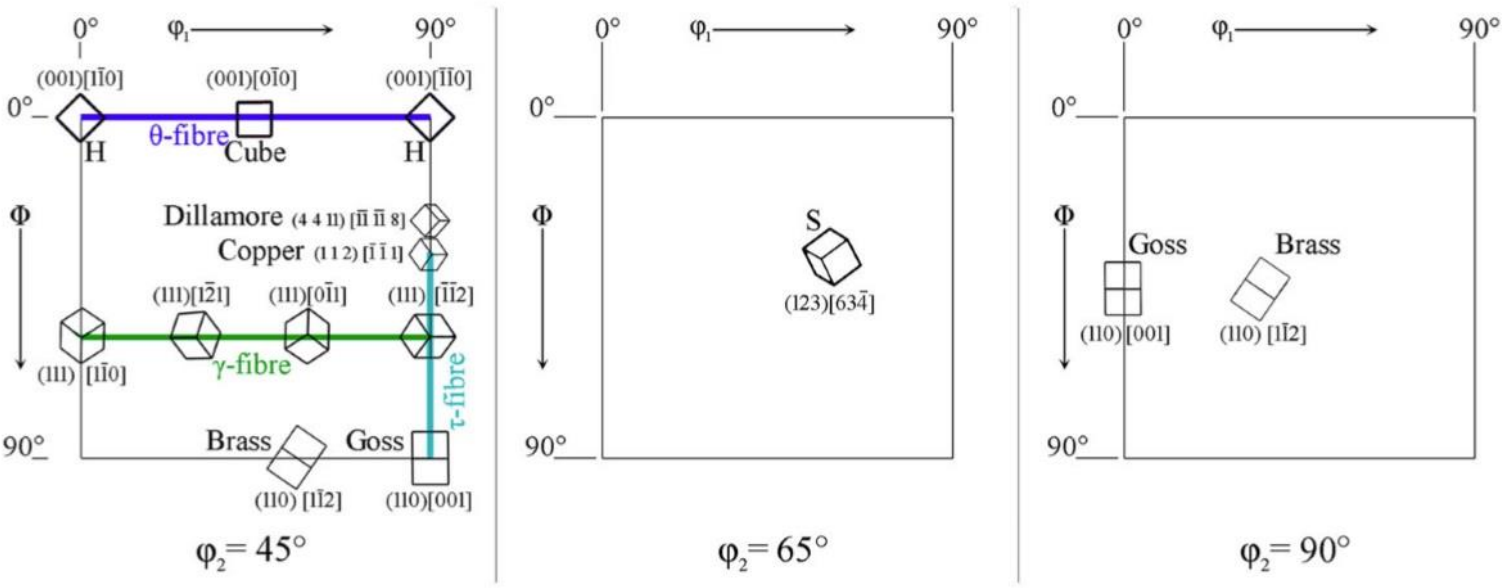

(b)

\begin{tabular}{lcl}
\hline Material & Nomenclature of fiber & Fiber axis \\
\hline FCC & $\alpha$ & $\langle 110\rangle \| \mathrm{ND}$ \\
& $\gamma$ & $\langle 111\rangle \| \mathrm{ND}$ \\
$\tau$ & $\tau$ & $\langle 110\rangle \| \mathrm{TD}$ \\
& $\beta$ & Not a fiber in true sense
\end{tabular}

(c)

Figure 17: Main texture fibres of FCC material - (a) as embedded in reduced Euler's space [23], (b) important $\phi 2$ sections representing characteristics components [25] and (c) fibre nomenclature and fibre axis [23] 


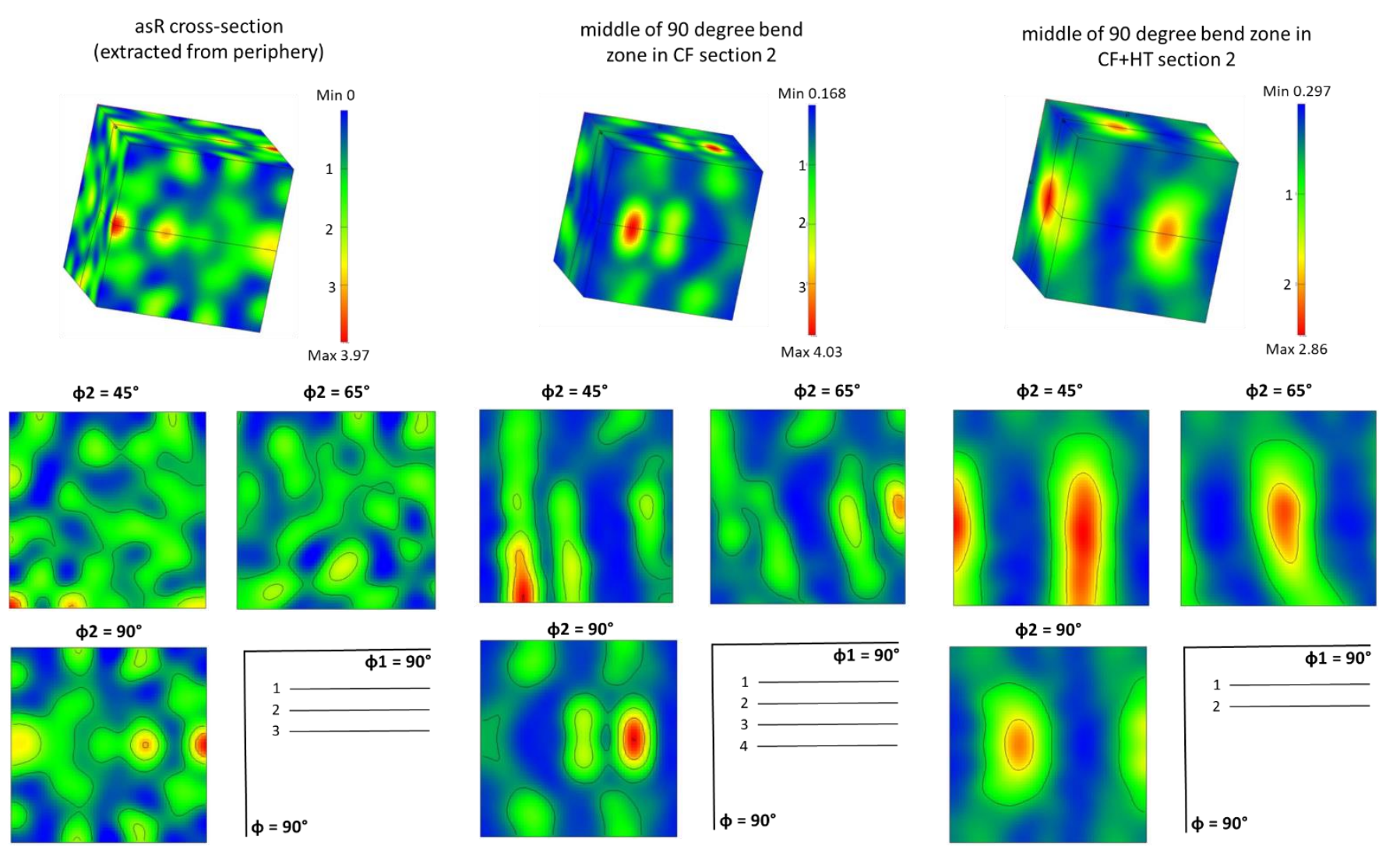

Figure 18: Evolution of ODF maps at $\phi 2=45^{\circ}, 65^{\circ}$ and $90^{\circ}$ sections of as $R$ cross-section and middle of 90 degree bend zone in both $C F$ section 2 and $C F+H T$ section 2

\subsection{Hardness analysis}

The plastic strain generated during cold rotary forging is not uniformly distributed throughout the part due to uneven deformation. This plastic deformation not only influences the microstructure but also changes material's strength at different region depending on the degree of deformation. This can be characterised by means of hardness mapping. Figure 19 shows the hardness distribution in asR cross-sections and corresponding hardness maps as observed at the centre (Figure 19a and Figure 19b) and the periphery (Figure 19c and Figure 19d) of the core cylinder. The hardness values of both the cross-sections were observed in the range of 250 - $295 \mathrm{HV}$ with a noticeable variation especially at the centre as compared to the periphery. This variation was attributed to the presence of grains with variable sizes at the centre rather than the periphery. Figure 20 shows the hardness distribution in all four sections of CF sample and corresponding hardness maps. The hardness was observed in the range of $395-445 \mathrm{HV}$ and 250 - $480 \mathrm{HV}$ in section1 (Figure 20a) and section2 (Figure 20c) respectively, followed by a rapid decrease in the range of $240-295 \mathrm{HV}$ in both section 3 and section 4 (Figure 20e and 
Figure 20g respectively). This change was also evident from the hardness maps (Figure 20b, Figure 20d, Figure 20f and Figure 20h). Similarly, Figure 21 shows the hardness distribution in all four sections of $\mathrm{CF}+\mathrm{HT}$ sample and corresponding hardness maps. The heat-treatment significantly improved the hardness distribution of section 3 and section4 in the range of $365-$ $395 \mathrm{HV}$ while retaining the hardness properties of other two sections in the range of $365-415$ $\mathrm{HV}$. Thus a uniform hardness distribution was observed in each of the four $\mathrm{CF}+\mathrm{HT}$ sections fulfilling the hardness requirement (>361 HV) as evident from the hardness maps (Figure 21b, Figure 21d, Figure 21f and Figure 21h). Here it should be noted that these hardness results are reproducible for the cold rotary forged flanges and the flanges after heat-treatment. This study includes the hardness analysis of only two flanges (i.e. one cold rotary forged flange and one after the heat-treatment) as randomly selected from a small batch of flanges forged together.
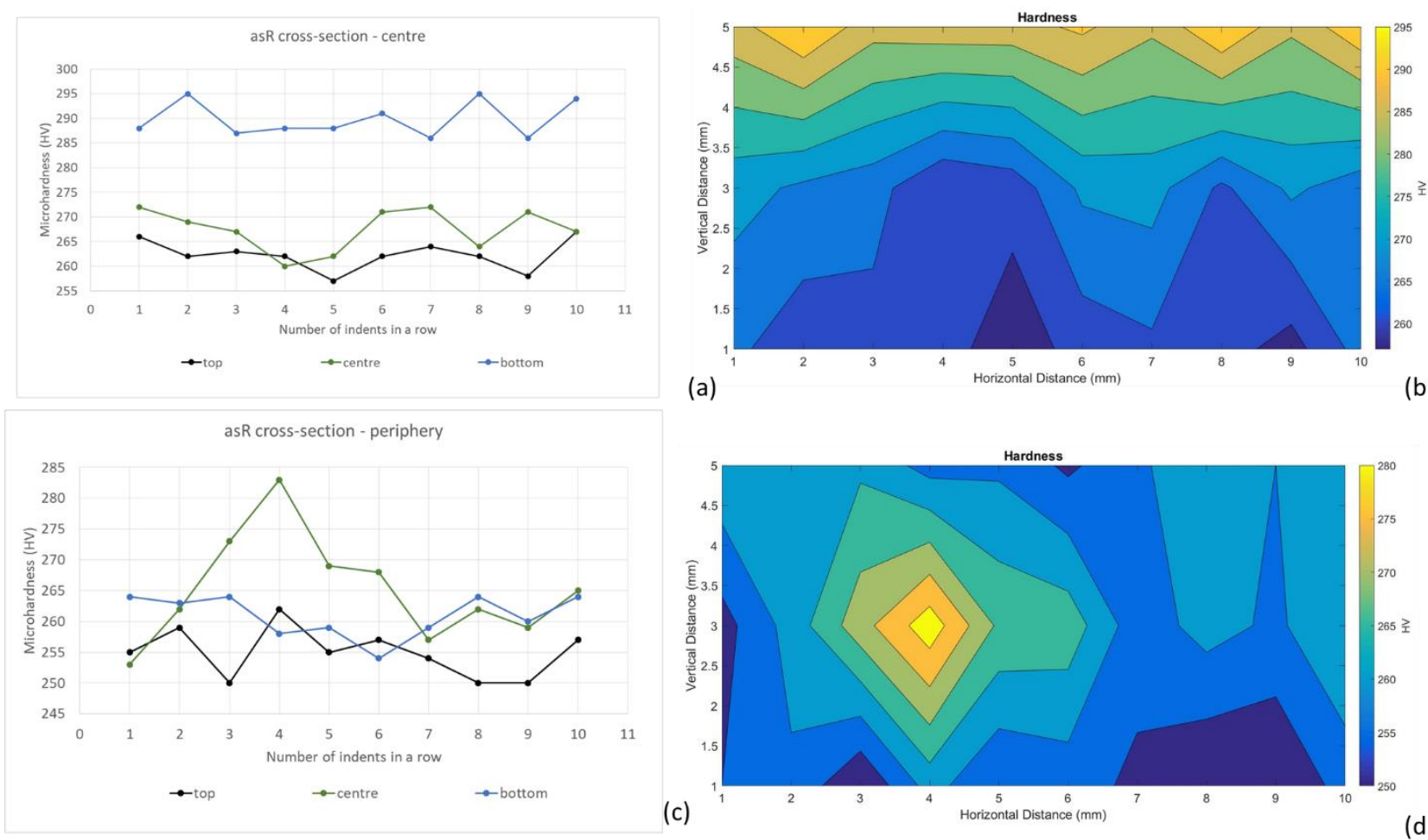

Figure 19: Hardness distribution in asR cross-sections and corresponding hardness maps (see Figure 6 for indent locations) - $(a, b)$ from centre and $(c, d)$ from periphery of the core cylinder 

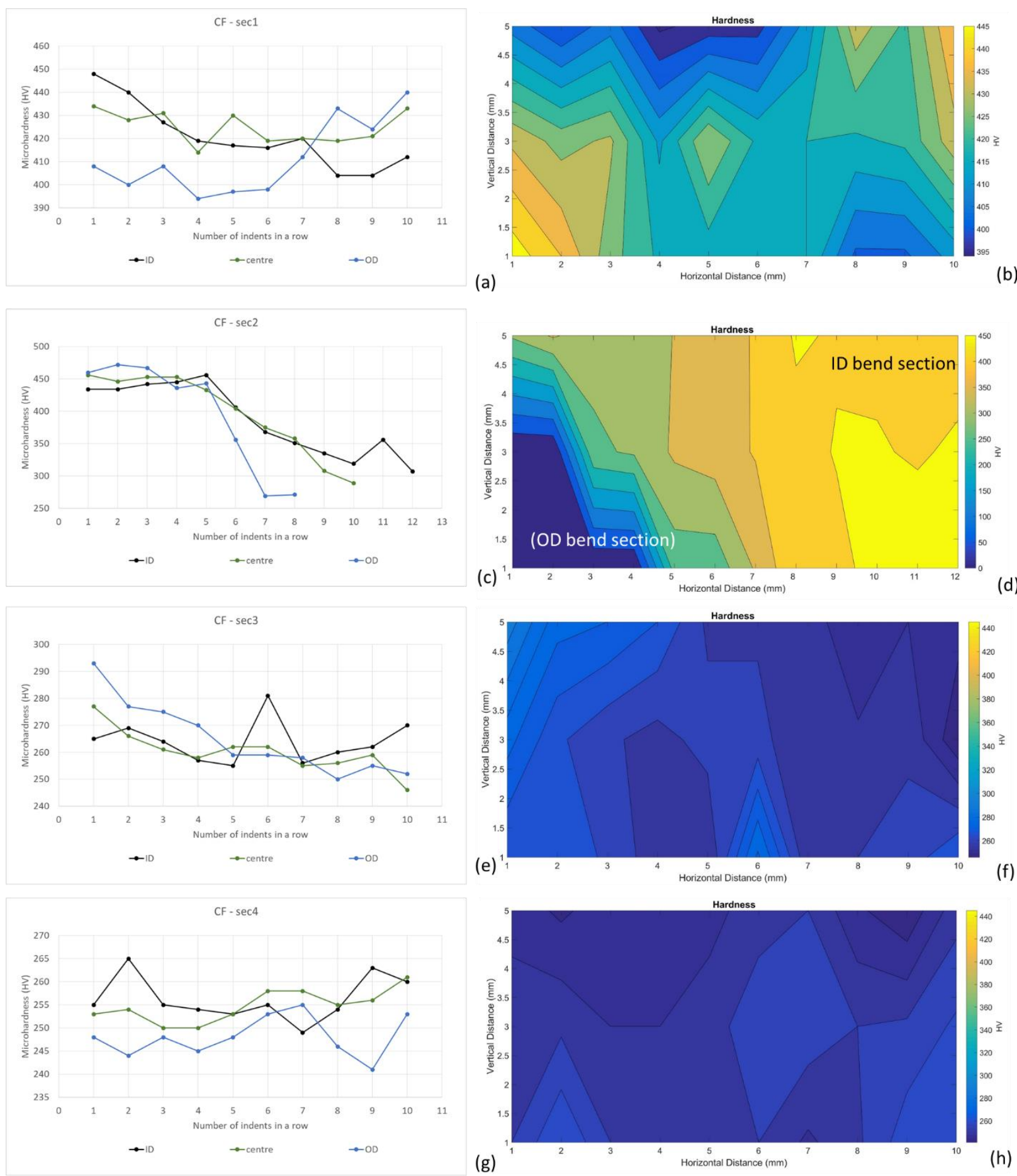

Figure 20: Hardness distribution in CF sample and corresponding hardness maps (see Figure 6 for indent locations $)-(a, b)$ section $1,(c, d)$ section $2,(e, f)$ section 3 and $(g, h)$ section 4 

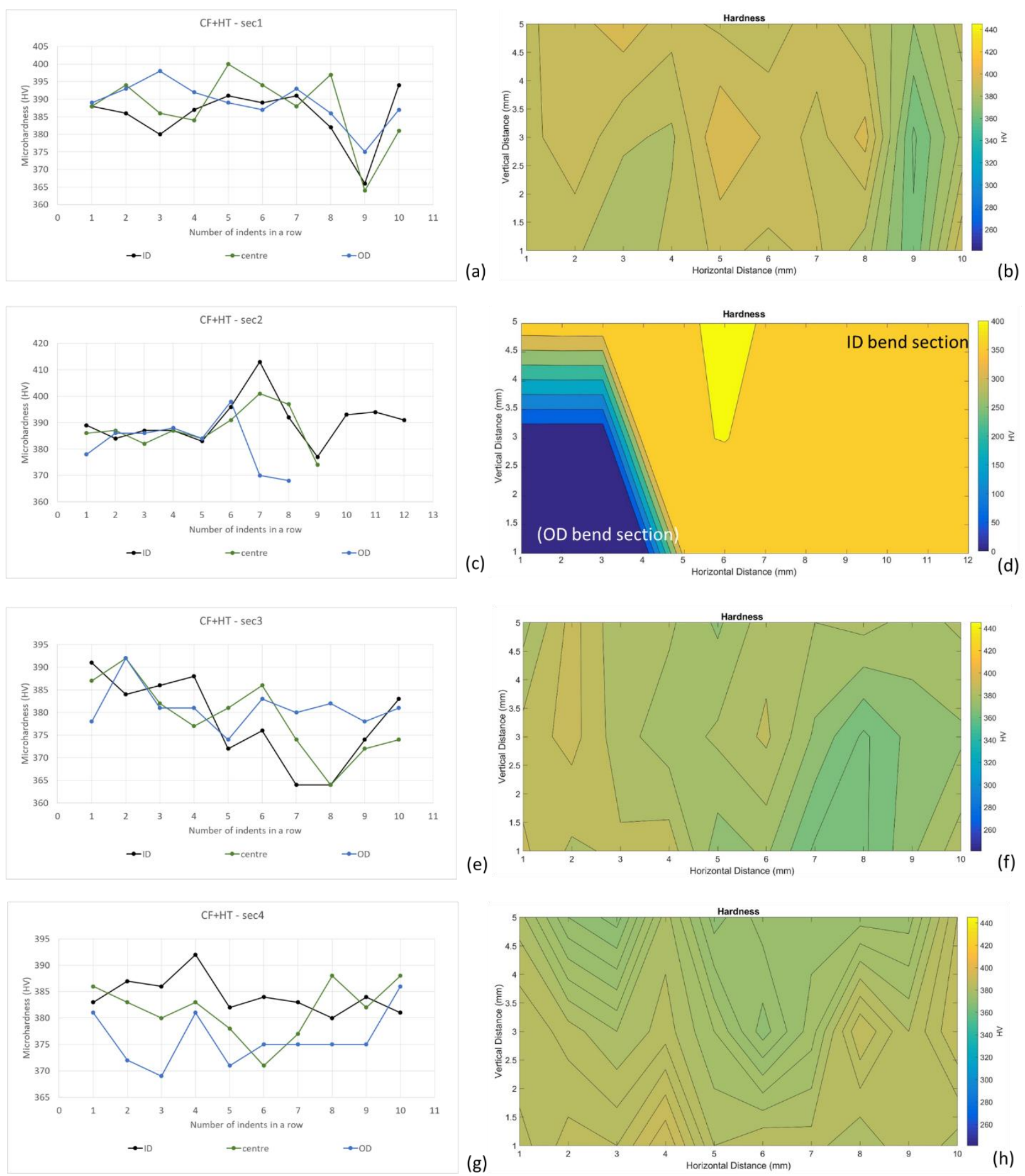

Figure 21: Hardness distribution in CF+HT sample and corresponding hardness maps (see Figure 6 for indent locations) - $(a, b)$ section $1,(c, d)$ section $2,(e, f)$ section 3 and $(g, h)$ section 4

Figure 22 summarises the average hardness values of all asR, CF and CF+HT sections together. The average hardness value of asR sample (including both cross-sections) was observed as $266.75 \pm 11.97 \mathrm{HV}$. After cold rotary forging, the highest hardness was observed in CF section1 
(419 $\pm 13.56 \mathrm{HV})$, followed by CF section2 (393.4 $\pm 63.26 \mathrm{HV})$, whereas significantly less hardness was observed in CF section3 and section4 $(262.97 \pm 9.88 \mathrm{HV}$ and $253.07 \pm 5.43 \mathrm{HV}$ respectively). It should be noted that the average hardness values of CF section 3 and section 4 were very similar to the asR material, as these CF sections had grain size similar to asR material and did not undergo any large deformation. On the other hand, both CF section1 and section2 experienced severe deformation (as evident from the heavily elongated grains observed in the region between CF sections 1 and 2, Figure 9) due to cold rotary forging leading to very high hardness values. The highest hardness of CF section1 was further influenced by its lowest average grain size $(\sim 10.07 \mu \mathrm{m})$. Overall $\mathrm{CF}$ section1 and section2 met the hardness requirement $(>361 \mathrm{HV})$, but the other sections did not. The heat-treatment introduced a homogeneous microstructure (average grain size in the range of $\sim 11.36-12.01 \mu \mathrm{m}$ ) without showing any grain refinement and therefore provides a uniform hardness distribution along the $\mathrm{CF}+\mathrm{HT}$ sections $1-4$ showing an average hardness of $387.3 \pm 7.99 \mathrm{HV}, 387.34 \pm 9.08 \mathrm{HV}$, $379.87 \pm 7.53 \mathrm{HV}$ and $380.60 \pm 5.65 \mathrm{HV}$ respectively. This improvement in hardness distribution was mainly attributed to the $\gamma^{\prime \prime}$ precipitation hardening caused by the heattreatment. Unlike CF sections, all four sections of the $\mathrm{CF}+\mathrm{HT}$ flange part met the hardness requirement $(>361 \mathrm{HV})$, thus indicating the advantage of this specific heat-treatment on cold rotary forged parts.

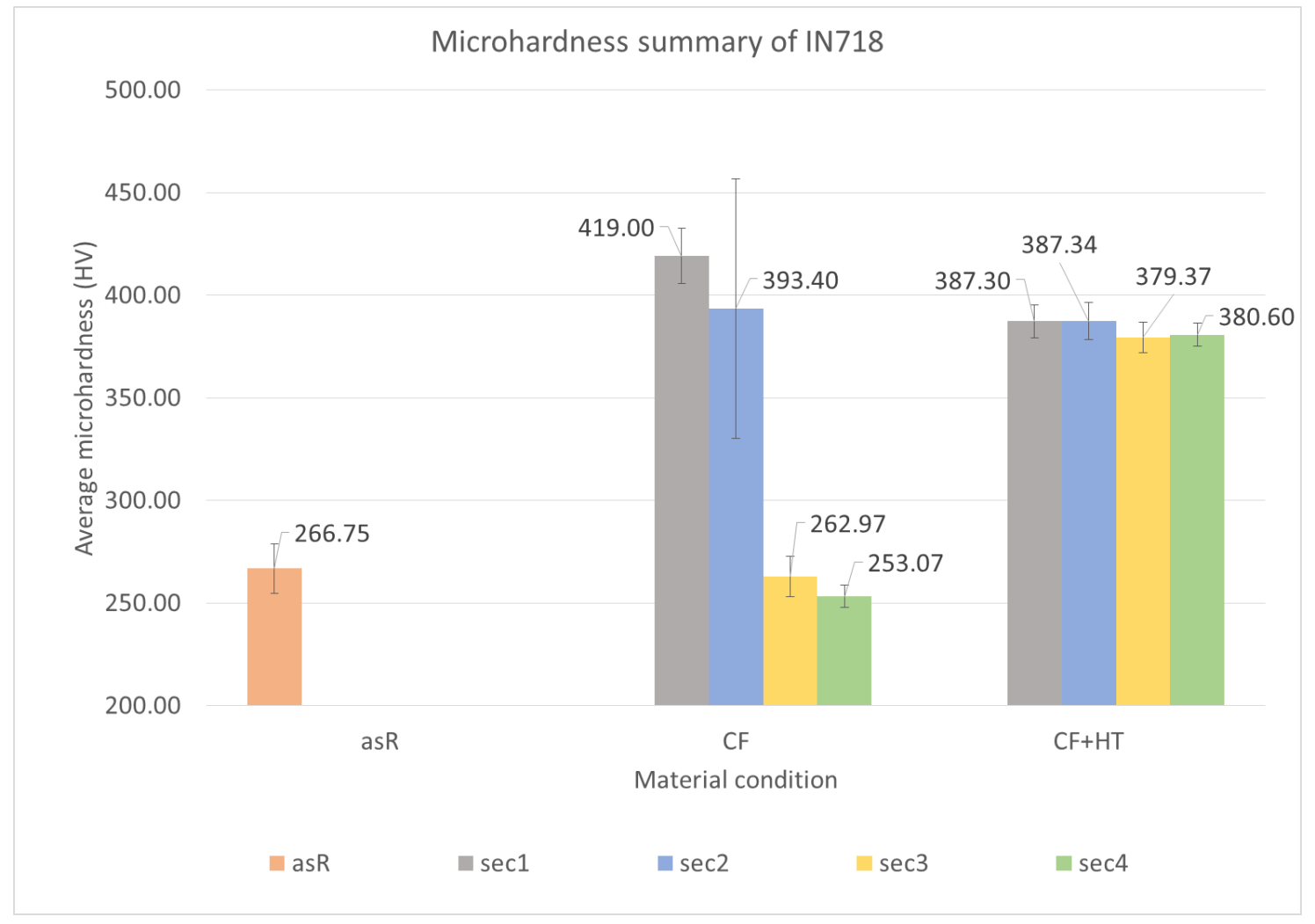


Figure 22: Hardness summary of asR, $C F$ and $C F+H T$ sections

\subsection{Surface roughness analysis}

Figure 23 summarises the surface roughness measurement of asR, $\mathrm{CF}$ and $\mathrm{CF}+\mathrm{HT}$ parts at different scan positions. Figure 23a shows the roughness values of asR part (here the asR part indicates the preform material, not the polished sample used for microstructural analysis) collected from the top surface and cross-section. Except one single scan, the other scans showed almost similar $\mathrm{R}_{\mathrm{a}}, \mathrm{R}_{\mathrm{q}}, \mathrm{R}_{\mathrm{z}}$ values in top surface and cross-section. Figure $23 \mathrm{~b}$ shows the roughness values of CF part collected from upper and lower flanges as well as inner and outer walls. No noticeable difference in roughness was observed at both the upper and lower flanges, however significantly higher roughness values were obtained from the inner wall section as compared to other positions. When compared to the preform material, a significant improvement in $\mathrm{R}_{\mathrm{a}}$ value was observed after cold rotary forging. Similarly, Figure 23c shows the roughness values of $\mathrm{CF}+\mathrm{HT}$ part and as expected, the roughness values of the CF part were slightly deteriorated after the heat-treatment. Figure 24 summarises the roughness values of asR, $\mathrm{CF}$ and $\mathrm{CF}+\mathrm{HT}$ parts. Both $\mathrm{CF}$ and $\mathrm{CF}+\mathrm{HT}$ parts showed much lower average surface roughness $\left(\mathrm{R}_{\mathrm{a}}\right)$ values when compared to the asR material (i.e. $2.58 \pm 1.34 \mu \mathrm{m}$ for the bar). The $\mathrm{R}_{\mathrm{a}}$ value was observed lowest in CF part $(0.42 \pm 0.25 \mu \mathrm{m})$, which was then increased to almost two times for $\mathrm{CF}+\mathrm{HT}$ part $(0.94 \pm 0.89 \mu \mathrm{m})$. The same trend was observed for $\mathrm{R}_{\mathrm{q}}$ and $\mathrm{R}_{\mathrm{z}}$ values. It should be noted that the $\mathrm{R}_{\mathrm{z}}$ values from the inner wall side (IW) are particularly very high as compared to all other scan positions. IW represents the inner side of the hollow preform cylinder after EDM cut, thus obviously showing higher roughness as compared to uncut (i.e. lower flange side and outer wall of flange as shown in Figure 7) and deformed areas (i.e. upper flange side as shown in Figure 7). 


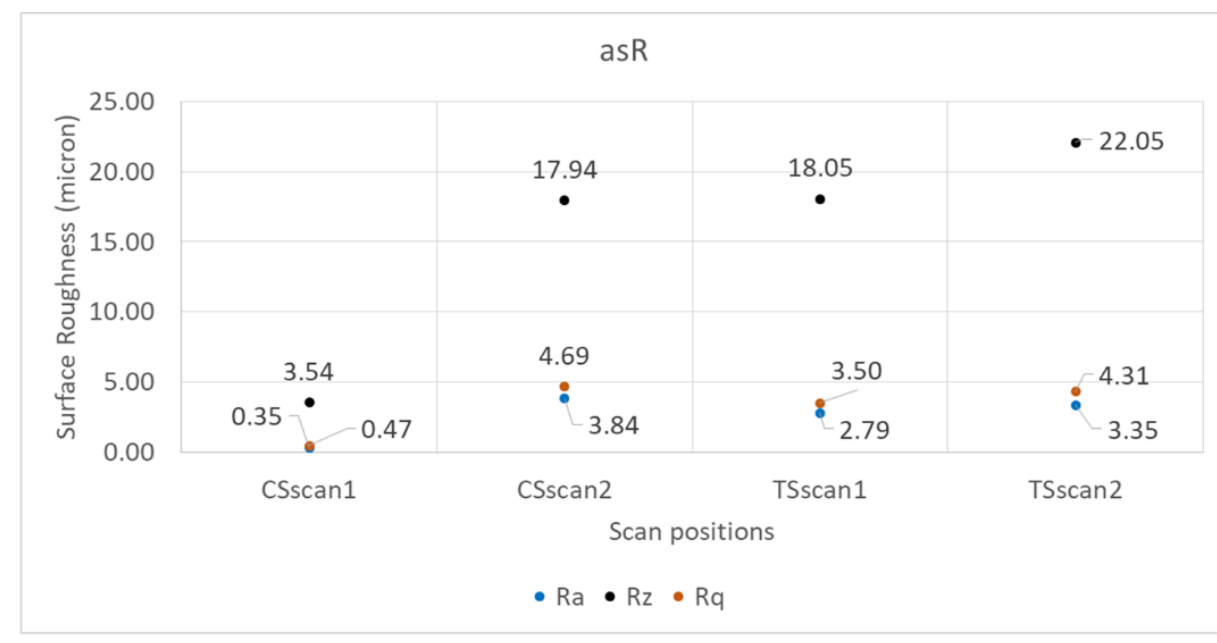

Abbreviations:

CSscan1 cross-section scan 1

CSscan2 cross-section scan2

TSscan1 Top surface scan1

TSscan2 Top surface scan2

(a)
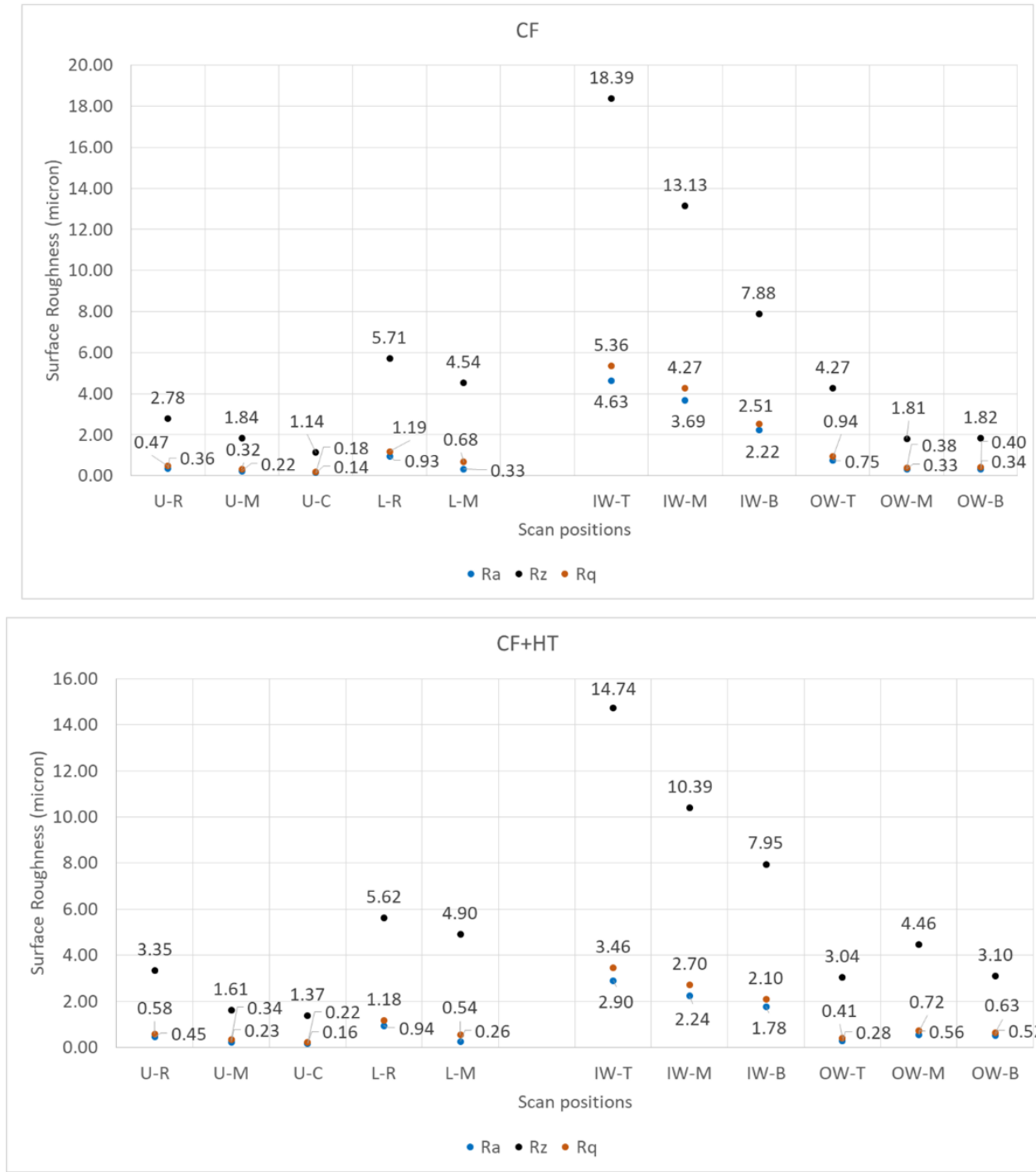

Abbreviations:

U-R Upper-round end

U-M Upper-mid

U-C Upper-cut end

(b) L-R Lower-round end

L-M Lower-mid

IW-T Inner wall-top

IW-M Inner wall-mid

IW-B Inner wall-bottom

OW-T Outer wall-top

OW-M Outer wall-mid

OW-B Outer wall-bottom

(c)

Figure 23: Surface roughness measurement (see Figure 7 for scan positions) of (a) asR, (b) $C F$ and (c) $C F+H T$ parts at different scan positions 


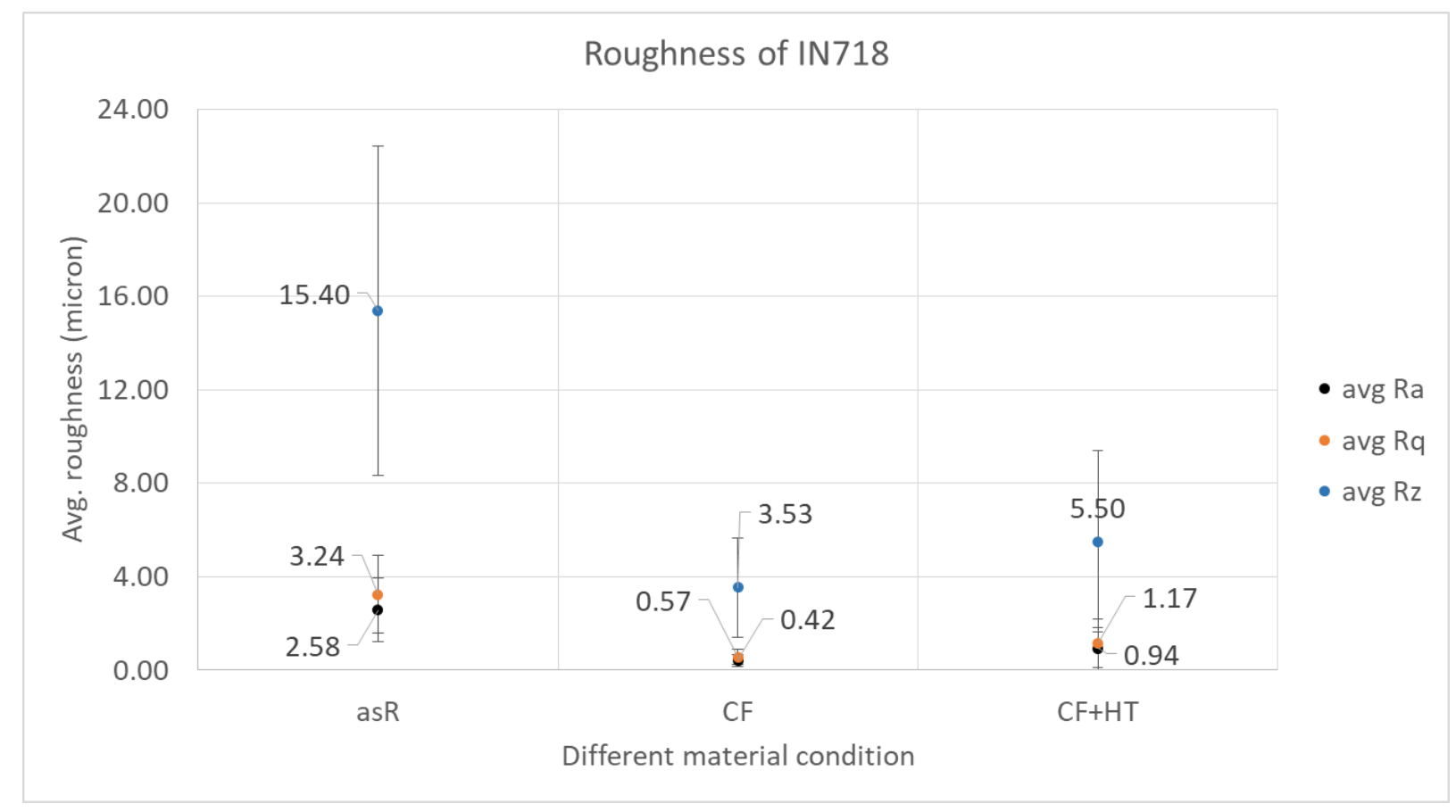

Figure 24: Surface roughness summary of asR, $C F$ and $C F+H T$ parts

\section{Discussion}

This work demonstrates that the cold rotary forging of Inconel 718 flange with a 90 degree bend is possible and the related microstructural characterisation indicates benefits of the chosen heat-treatment in terms of providing a homogenous microstructure, a uniform hardness distribution and improved surface roughness to the CF flange. Cold rotary forging imparts permanent deformation in some parts of the hollow IN718 cylinder, especially the deformation is observed severe at the flange (i.e. section1) and at the 90 degree bend of the flange part (i.e. section2). The deformation is observed considerably lower at $\mathrm{CF}$ sections 3 and 4 resulting in a non-uniform plastic strain distribution throughout the flange. This uneven deformation along the entire flange section indicates that the material is mostly strain hardened at CF sections 1 and 2 as compared to the rest leading to a substantial change in the properties from one section to another. Compared to the asR material, no noticeable grain refinement is observed after cold rotary forging (with an average grain size in the range of $\sim 10.07-12.76 \mu \mathrm{m}$ ) except formation of significantly elongated grains and some disruption to the material flow at the bottom corner of section2. The EBSD analysis conducted on the middle of severely deformed 90 degree bend zone in CF section2 indicates the presence of highly strained elongated grains with reduced size (an average grain size of $6.51 \pm 3.95 \mu \mathrm{m}$ ) when compared to the asR condition (an average 
grain size of $10.9 \pm 6.77 \mu \mathrm{m})$. Cold rotary forging also significantly improves the surface roughness $\left(\mathrm{R}_{\mathrm{a}}\right.$ of $\left.\sim 0.42 \pm 0.25 \mu \mathrm{m}\right)$ as compared to the as $\mathrm{R}$ material condition $\left(\mathrm{R}_{\mathrm{a}}\right.$ of $\sim 2.58 \pm$ $1.34 \mu \mathrm{m})$. When hardness is considered, the most strain-hardened CF sections 1 and 2 meet the hardness requirement (>361 HV) due to their high average hardness values $(419 \pm 13.56 \mathrm{HV}$ and $393.4 \pm 63.26 \mathrm{HV}$ respectively) and the highest hardness of CF section1 is further influenced by its lowest average grain size $(\sim 10.07 \mu \mathrm{m})$. This strain hardening in section 2 is clearly evident from the EBSD analysis showing a significant increase in the amount of substructured and deformed grains (36\% and 55.5\% respectively), which indicates the subdivision of elongated grains due to severe deformation resulting in considerable grain refinement. This is further supported by KAM map showing presence of higher level of average misorientation, i.e. strain, in section2. Though asR material doesn't contain any characteristics fibres of FCC material, however the deformation during cold rotary forging imposes a fibre-type texture in the $\mathrm{CF}$ sample. The $\tau$-fibre was appeared at $\phi 2=45^{\circ}$ section and both the Brass and $\mathrm{S}$ texture components (at $\phi 2=45^{\circ}$ and $65^{\circ}$ sections respectively) became much stronger as compared to the asR material. On the other hand, the average hardness values of CF sections 3 and 4 (262.97 $\pm 9.88 \mathrm{HV}$ and $253.07 \pm 5.43 \mathrm{HV}$ respectively) are found very similar to the asR material as these CF sections do not undergo any large deformation and contain grain size similar to as material. This inconsistency in hardness distribution indicates that the $\mathrm{CF}$ flange requires heat treatment to restore homogeneity.

The heat-treatment applied on the $\mathrm{CF}$ flange is found very effective in achieving a homogeneous microstructure and a uniform hardness distribution throughout the flange section meeting the hardness requirement $(>361 \mathrm{HV})$. The heat-treatment eliminates the twins and neutralises the difference in the average grain size of CF sections leading to formation of a homogeneous and equiaxed microstructure throughout the heat-treated flange (an average grain size of $\sim 11.36-12.01 \mu \mathrm{m})$. Typically the dominant deformation mechanism for low SFE materials is recrystallization, which is clearly observed in the 90 degree bend zone of CF+HT section2, where elongated grains generated during cold rotary forging are recrystallized after heat-treatment leading to significant grain refinement (an average grain size of $3.62 \pm$ $1.11 \mu \mathrm{m})$. The recrystallization is evident from the EBSD analysis, which shows a significant increase in the amount of recrystallized grains (67.9\%) and subsequent decrease in the amount of sub-structured and deformed grains (27.1\% and 5.04\% respectively) after the heat-treatment. The decrease in strain level after heat-treatment is also evidenced from the KAM map of 
section2. Simultaneously a substantial change in the texture is observed with a drop in the texture strength. The locations of both $\tau$-fibre and $S$ texture component (at $\phi 2=45^{\circ}$ and $65^{\circ}$ sections respectively) were shifted towards left as compared to the CF section and a strong Brass component was appeared at $\phi 2=90^{\circ}$ section. In addition to this, the double aging treatment promotes formation of $\gamma^{\prime \prime}$ phase resulting in an increase of overall hardness by precipitation hardening principle. Moreover, the $\gamma^{\prime \prime}$ precipitates are effective in hindering the grain growth by pinning the boundaries hence providing more strength from this perspective. This is evident from the hardness distribution and average hardness values of sections $1-4$ of the $\mathrm{CF}+\mathrm{HT}$ flange. The heat-treatment slightly increases the average grain size of $\mathrm{CF}$ section1 but simultaneously reduces the average grain size of CF sections $2-4$. Furukawa et al. [27] showed that a decrease in grain size led to an increase in material hardness and vice versa according to the Hall-Petch relationship, which is apparent in the present case. The average hardness of $\mathrm{CF}+\mathrm{HT}$ section1 is slightly decreased to $387.3 \pm 7.99 \mathrm{HV}$ compared to its $\mathrm{CF}$ counterpart, whereas the average hardness of $\mathrm{CF}+\mathrm{HT}$ sections 3 and 4 is significantly increased to $379.87 \pm 7.53 \mathrm{HV}$ and $380.60 \pm 5.65 \mathrm{HV}$ respectively. The significant hardness variation within the $\mathrm{CF}$ section 2 is also eliminated by precipitation hardening resulting in an average hardness of $387.34 \pm 9.08 \mathrm{HV}$ after heat-treatment. Overall, the heat-treatment promotes a homogeneous microstructure with an improved surface roughness $\left(\mathrm{R}_{\mathrm{a}}\right.$ of $\left.\sim 0.94 \pm 0.89 \mu \mathrm{m}\right)$ and provides uniformity of the hardness distribution throughout the cold rotary forged flange meeting the hardness requirement ( $>361 \mathrm{HV})$.

\section{Conclusions}

Following conclusions are drawn from this work:

- The Inconel 718 material can be cold rotary forged into near net-shape axisymmetric component with a 90 degree bend flange. This demonstrates that a significant material saving can be achieved through the aforementioned manufacturing route as compared to machining a billet into net-shape final geometry.

- The deformation mechanisms in the severely deformed 90 degree bend zone resulting from the cold rotary forging is comparable to that in the case of shear zones of ECAP processed billets after the first pass. This is because the process directionality and the nature of deformation is similar in both cases. This causes $40-50 \%$ reduction in grain size and similar increase in hardness values in cases of both these processes. 
- The heat treatment given to the cold rotary forged Inconel 718 flange part results in homogenous equiaxed microstructure throughout the flange part. It also causes hardening of areas with less or no strain through $\gamma^{\prime \prime}$ precipitation and causes slight softening of those areas with high strain through recrystallization. This ultimately results in homogenous hardness distribution throughout the whole component.

\section{Acknowledgement}

The authors would like to acknowledge Rolls Royce Plc for funding this work from their Innovate UK: Aerospace Technology Institute - Strategic R\&D Project grant (application no. 66733-263147) titled "Manufacturing Portfolio Project 2: Manufacture of Advanced Materials". This work in particular was sub-contracted from Rolls Royce Plc to Advanced Forming Research Centre (AFRC) from the I-UK grant under ETC-00942. The authors would also like to acknowledge the help of Mr. Kyle Watt, Manufacturing engineer at the AFRC, for providing useful information on the cold rotary forging operation.

\section{References}

[1] Semiatin, S. Rotary Forging. In: ASM Handbook, Volume 14A: Metalworking: Bulk Forming. 2005, p. 179-182.

[2] Han X, Hua, L. Comparison between cold rotary forging and conventional forging. Journal of Mechanical Science and Technology. 2009; 23: 2668-2678.

[3] Aksenov LB, Kunkin SN. Rotary Forging of Hollow Components, In: Advances in Mechanical Engineering - Lecture Notes in Mechanical Engineering. 2015; pp. 1-5.

[4] Han X, Dong L, Hua L, Zhuang W. Microstructure and texture evolution in cold rotary forging of spur bevel gears on 20CrNiMnTi alloy steel. Journal of Materials Engineering and Performance. 2016; 25(3): 1182-1190.

[5] Pérez M. Microstructural and texture evolution of Jethete M152 flanged-test pieces during cold rotary forging. Journal of Materials Processing Technology. 2018; 252: 582-594.

[6] Slama C, Abdellaoui M. Structural characterization of the aged Inconel 718. Journal of Alloys and Compounds. 2000; 306: 277-284.

[7] Akca E, Gursel A. A Review on Superalloys and IN718 Nickel-Based Inconel Superalloy. Periodicals of Engineering and Natural Sciences. 2015; 3(1): 15-27.

[8] Domblesky JP, Shivpuri R. Grain Size Modelling and Optimization of Rotary Forged Alloy 718. Journal of Engineering Materials and Technology. 1997; 119: 133-137.

[9] Zhong-Qi Y, Qiu M, Zhong-qin L. Simulation and Analysis of Microstructure Evolution of IN718 in Rotary Forgings by FEM. Journal of Shanghai Jiaotong University (Science). 2008; 13(6): 721-726. 
[10] Mangas A, Santos M, Jose JS, Atxaga G, Adarraga O. Microstructural behaviour in Rotary Forging of Inconel 718. Key Engineering Materials. 2012; 504-506: 169-174.

[11] Loyda A, Hernández-Muñoz GM, Reyes LA, Zambrano-Robledo P. Microstructure Modeling of a Ni-Fe-Based Superalloy During the Rotary Forging Process. Journal of Materials Engineering and Performance. 2016; 25: 2128-2137.

[12] Candioto KCG, Caliari FR, Reis DAP, Couto AA, Nunes CA. Characterization of the Superalloy Inconel 718 after Double Aging Heat Treatment. Mechanical and Materials Engineering of Modern Structure and Component Design. 2015; 293-300.

[13] Wang C, Li R. Effect of double aging treatment on structure in Inconel 718 alloy. Journal of Materials Science. 2004; 39(7): 2593-2595.

[14] Kishan EVR, Nagarajan NM. Strengthening of Forged Inconel Superalloy by Age Hardening Heat Treatment. International Journal of Innovative Science, Engineering \& Technology. 2015; 2(8): 387-391.

[15] Maj P, Adamczyk-Cieslak B, Slesik M, Mizera J, Pieja T, Sieniawski J, Gancarczyk T. Dudek S. The Precipitation Processes and Mechanical Properties of Aged Inconel 718 Alloy After Annealing. Archives of Metallurgy and Materials. 2017; 62(3): 1695-1702.

[16] ASTM International. Standard Test Methods for Determining Average Grain Size (Designation: E112 - 13). 2016.

[17] Humphreys FJ. Characterisation of fine-scale microstructure by EBSD. Scripta Materialia. 2004; 51(8): 771-776.

[18] Saraf L. Kernel Average Misorientation Confidence Index Correlation from FIB Sliced Ni-Fe-Cr alloy Surface. Microscopy and Microanalysis. 2011; 17(S2): 424-425.

[19] Vickers Hardness Testing. www.struers.com, https://www.struers.com/enGB/Knowledge/Hardness-testing/Vickers\#

[20] ASTM International. Standard Test Method for Knoop and Vickers Hardness of Materials (Designation: E384 - 11). 2015.

[21] Chrominski W, Olejnik L, Rosochowski A, Lewandowska M. Grain refinement in technically pure aluminium plates using incremental ECAP processing. Materials Science \& Engineering A. 2015; 636: 172-180.

[22] Wright SI, Nowell MM, Field DP. A Review of Strain Analysis Using Electron Backscatter Diffraction. MicroscopyAND Microanalysis. 2011; 17: 316-329.

[23] Suwas S, Ray RK. Representation of Texture. In: Crystallographic Texture of Materials. Springer-Verlag London. 2014, pp. 11-38.

[24] Wenk HR, Houtte PV. Texture and Anisotropy. Reports on Progress in Physics. 2004; 67: 1367-1428.

[25] Kestens LAI, Pirgazi H. Texture formation in metal alloys with cubic crystal structures. Materials Science and Technology. 2016; 32(13): 1303-1315.

[26] Chen Z, Peng R, Moverare J, Avdovic P, Zhou JM, Johansson S. Surface Integrity and Structural Stability of Broached Inconel 718 at High Temperatures. Metallurgical and Materials Transactions A. 2016; 47A(7): 3664-3676.

[27] Furukawa M, Horita Z, Nemoto M, Valiev RZ, Langdon TG. Microhardness measurements and the Hall-Petch relationship in an Al-Mg alloy with submicrometer grain size. Acta Materialia. 1996; 44 (11): 4619-4629. 